\title{
O que se entende por Retórica da Guerra Cultural
}

\author{
What is Rhetoric of Culture Wars ${ }^{1}$ ?
}

Frederico Rios C. dos SANTOS*

\begin{abstract}
RESUMO: O presente trabalho tem como objetivo chegar a uma caracterização do que se denomina aqui por Retórica da Guerra Cultural. Por meio de algumas categorias da Retórica, da noção de contrato de comunicação, de regras do suporte, do estilo, do debate e da argumentação propostas por alguns cientistas da linguagem, a análise recai sobre o corpus de apoio representado por postagens em redes sociais em dois momentos de polêmica pública no Brasil contemporâneo: o da Vaza-Jato e o do atentado a Jair Bolsonaro quando era candidato a presidente da República. Chegou-se a algumas constantes sobre o que serviria de parâmetro de definição da dita Retórica da Guerra Cultural, o que pode futuramente ser testado por meio outros corpora e contextos de análise.
\end{abstract}

PALAVRAS-CHAVE: Retórica. Guerra Cultural. Argumentação. Discurso. Brasil.

\begin{abstract}
The present work aims to characterize what is called here Rhetoric of Culture Wars. Through some categories of Rhetoric, the notion of communication contract, rules of support, style, debate, and argumentation proposed by some language scientists, one analyses the corpus represented by social network posts in two moments of public controversy in contemporary Brazil: Vaza-Jato and the attack on Jair Bolsonaro when he was a candidate to the Brazilian presidency. Some constants have been reached about to the supposed defining parameter of the so-called Rhetoric of Culture Wars, which can be further tested by using other corpora and contexts of analysis.
\end{abstract}

KEYWORDS: Rhetoric. Culture Wars. Argumentation. Discourse. Brazil.

\footnotetext{
* Doutor em Linguística do Texto e do Discurso (UFMG, 2019). Pesquisador na Universidade de São Paulo. ORCID: https://orcid.org/0000-0002-0496-8452. fredericodesantos@gmail.com

1 Preferiu-se aqui traduzir "retórica da guerra cultural" por "rhetoric of culture wars", para manter a tradição de obras célebres como The Rhetoric of reaction, de Hirschman, e Culture wars, de Hunter.
} 


\section{Introdução}

A origem do termo "guerra cultural" é controversa. Foi nos Estados Unidos, no entanto, que a expressão se tornou popularizada, através da publicação de Culture Wars, de James Davison Hunter, em 1991. Trata-se da descrição do embate entre duas visões de mundo antagônicas, uma conservadora (também chamada de ortodoxa ou tradicionalista), associada à direita política, e outra progressista, relacionada, predominantemente, às esquerdas, mas não só. A guerra cultural traz em seu bojo problemas de ordem social e moral que dizem respeito, por exemplo, à sexualidade, ao comportamento, à raça, à religiosidade etc., implicando ainda questões políticas e econômicas.

Do ponto de vista da linguagem, pergunta-se: tendo em vista esses embates culturais na sociedade, existiria uma retórica que lhe seja peculiar? Seria possível pensar em algumas regularidades, ainda que essa guerra assuma contornos próprios em diferentes países e períodos históricos?

Para tentar responder a essas questões, este artigo se utiliza, como corpus de apoio, de postagens em redes sociais (Twitter e Facebook) em dois contextos brasileiros contemporâneos em que se presenciou uma polêmica pública: o episódio do atentado à facada ao então candidato à presidência da República, Jair Bolsonaro; e o período marcado pelo vazamento, pelo jornal The Intercept Brazil, de mensagens trocadas pelas autoridades da operação da Polícia Federal denominada Lava-Jato.

Com o auxílio de cientistas da linguagem, como Amossy (2014), Angenot (2008), Charaudeau (2005), Danblon (2004), Lima (2006), Maingueneau (2008), entre outros, buscar-se-á responder a essas questões através de algumas categorias da Retórica (entendida no âmbito do discurso), da noção de contrato de comunicação, de regras do suporte, do estilo, do debate e da argumentação, principalmente levando-se em conta um debate público afeito a sociedades abertas e democráticas. 
O artigo começa com uma primeira seção, em que se procura problematizar as origens do conceito de "guerra cultural", para, em seguida, no próximo tópico, trabalhar com essa noção do ponto de vista da linguagem. A tentativa é a de buscar alguma generalização possível para o fenômeno, ou, pelo menos, lançar as bases para que outros pesquisadores, por meio de outros corpora, inseridos em outros contextos de enunciação, confirmem ou contestem os resultados.

Espera-se, assim, que o trabalho possa contribuir não só para os cientistas da linguagem que procurem pensar a Retórica da Guerra Cultural, mas também, apesar de não ser o foco da pesquisa, que possa inspirar indiretamente educadores para refletirem sobre modelos educativos voltados à argumentação em democracias, que pressupõe a crítica responsável, a tolerância e o pluralismo, necessários para a permanência de suas instituições.

\section{As origens do conceito de "guerra cultural"}

A ideia de "guerra cultural" é controversa, seja no que diz respeito à origem do termo, seja em relação ao próprio conceito de cultura, cuja semântica é bastante fluida. Para Gross (1997), a expressão "guerra cultural" teria raízes no Kulturkampf, um episódio relacionado ao Segundo Reich alemão, no final do século XIX, quando Bismarck promoveu uma campanha cultural contra a investida do catolicismo no país recém-unificado. Em reação à ortodoxia da moral cristã, o chanceler almejava modernizar a sociedade alemã, secularizando-a, para impedir o avanço dos interesses papais nos assuntos do Estado. Travou-se, então, verdadeira guerra cultural, cujo troféu seria a conquista simbólico-psicológica da opinião pública (GROSS, 1997).

Entretanto, o conceito de guerra cultural é comumente considerado como uma importação dos EUA. De acordo com Sayuri (2019), o termo ganhou projeção quando, em 1989, a Universidade de Stanford promoveu a inclusão de autores indígenas no curso de Cultura Ocidental, como a guatemalteca Rigoberta Menchú Tum, ganhadora 
do Prêmio Nobel da Paz em 1992. Republicanos conservadores, em reação, protestaram, afirmando se tratar de um sintoma da degeneração da Cultura Ocidental. Na mesma época, uma exposição do fotógrafo americano Robert Mapplethorpe na Corcoran Gallery of Art, em Washington, sobre o universo underground gay, causou comoção em alguns setores reacionários da sociedade norte-americana. O grande debate girou em torno do financiamento público de artistas com obras de tal natureza (BAYLEY, 2016), como também acontece no Brasil, no caso da Lei Rouanet, a Lei Federal de Incentivo à Cultura n. 8.313/199, quando se quer atacar artistas considerados de um campo oposto da batalha cultural, sob o pretexto de não serem "talentosos" ou não produzirem "arte de verdade" (GALAHARDO, 2019).

Tal contexto norte-americano foi analisado pelo sociólogo James Davison Hunter, que lançou o livro Culture Wars, em 1991, para descrever o embate entre uma visão conservadora (ortodoxa ou tradicionalista também são termos empregados), associada à direita, e outra progressista, mais associada à esquerda (mas não unicamente). A batalha cultural mobiliza problemas de ordem social e moral, relacionados a sexualidade, comportamento, raça, religiosidade etc., mas que também impacta em discussões políticas e econômicas (SAYURI, 2019). Por exemplo, defender a intervenção do Estado na economia pode não ser, necessariamente, um debate típico de um cenário de guerra cultural, mas pode sê-lo considerando que a presença do Estado na economia é importante para garantir ações afirmativas para minorias alijadas do poder (político, econômico etc.), como mulheres, negros ou a população LGBT. Portanto, apesar da palavra "cultural" do termo "guerra cultural", a batalha transcende elementos estritamente culturais.

Eduardo Wolf, por sua vez, que está para publicar um livro sobre o assunto, mas cujo texto ainda não se encontra disponível, enfatiza, em entrevista ao jornal Nexo, o aspecto difuso desse tipo de conflito, uma vez que não se restringe a partidos, mas remete a aspectos simbólicos e valorativos que um grupo quer impor sobre o outro, 
sem que as razões alheias sejam levadas em consideração no debate. O objetivo maior seria silenciar a outra parte:

\begin{abstract}
"Guerra cultural" se refere a um tipo especial de tensão social e política em determinada sociedade. Como o nome diz, esse conflito ocorre na dimensão da cultura - da produção artística, pensamento e reflexão, no universo dos valores e símbolos. Não é como uma guerra civil, que representa um estágio avançado de deterioração do quadro social e institucional. Tampouco se reduz a um conflito de facções partidárias. Justamente por ser um fenômeno do campo da cultura, podemos perceber sua presença de maneira ampla e difusa na sociedade. O que torna esse tipo de tensão diferente é uma percepção, por parte de grupos majoritários ou dominantes, de que as nações e as sociedades em que vivem têm uma unidade e uma identidade que se traduzem em uma essência inalterável. Obviamente, tudo o que divergir dessa visão essencialista (pode ser do Brasil, pode ser do Ocidente), será considerado como uma ameaça radical, pois coloca em xeque a suposta identidade tradicional. Nesse contexto, os próprios indivíduos que desafiam a visão essencialista costumam ver sua missão em termos idênticos, só que com sinal trocado: a existência continuada da sociedade tradicional, com suas ortodoxias características, é um inimigo intolerável, um impedimento à própria existência da cultura desafiante. E é isso o que define a guerra cultural: não é uma disputa entre duas concepções políticas que se alternam no poder, não é uma divergência profunda quanto a leis ou a políticas públicas, mas sim uma "luta pela alma da nação", e cada lado só pode almejar o silêncio do outro (WOLF, apud SAYURI, 2019).
\end{abstract}

Já Esther Solano, professora da Unifesp, sublinha o fato de que a guerra cultural, tal como se conhece hoje, tenha surgido como reação à visibilidade de grupos minoritários do ponto de vista político, que antes não tinham expressividade no espaço público, como o movimento LGBTI, com sua campanha pelo casamento igualitário, o movimento negro e o movimento feminista, com pautas como equiparação de salários e o direito ao aborto, questão que mobiliza valores relacionados à religião:

A literatura estadunidense indica uma reação ao momento de avanço dos movimentos feministas, do movimento negro e de defesa dos direitos humanos no debate cultural, social e político, isto é, uma 
reação dos conservadores a tudo isso. Neste contexto, a "guerra cultural" é basicamente a moralização do debate público e, portanto, a moralização do debate político. Assim, os assuntos são abordados a partir do ponto de vista moral e religioso, desviando de questões programáticas e importantes para a vida pública (SOLANO, apud SAYURI, 2019).

Para Dejean (1989), teria sido também nos EUA do século XX, mas com a figura de Patrick Buchanan, um político do Partido Republicano, que o termo "guerra cultural" ganhou notoriedade. Em convenção republicana na qual almejava se lançar para a campanha presidencial de 1992, Buchanan incitou seus compatriotas conservadores à "guerra cultural pela alma americana", uma espécie de cruzada moral que oporia conservadores/religiosos, de um lado, e liberais políticos/seculares, de outro (WILLIAMS, 1997). Como ressalta Quadros,

[...] de um lado da trincheira repousaria a 'América profunda', crente, comunitarista, tradicional e conservadora. De outro, a sociedade cosmopolita impregnada pela secularização, pelo individualismo e pelo relativismo moral alegadamente estimulado por determinadas esquerdas (QUADROS, 2015, p. 165).

Os temas levantados na época por Buchanan, bem como o seu léxico empregado, constituem constantes dos embates culturais contemporâneos no Brasil e no mundo. Com a exposição de alguns pontos de seu pensamento conservador, é possível também inferir as pré-compreensões do grupo progressista adversário.

Intitulando-se "conservador tradicional", Buchanan se insurgia contra os chamados "neoconservadores", para ele conservadores que não poderiam ser considerados como de pleno título. Buchanan acusava esse tipo de conservador, que à sua época seria predominante no Partido Republicano, como "extraterrestres sem documento provindos da esquerda, carregando consigo o vírus do estatismo e do globalismo", mas que romperam com a esquerda por ocasião da Guerra do Vietnã ao entrarem para a administração Reagan (PAT BUCHANAN'S, 1999). 
Importante observar que esse termo "globalismo" não se confunde com "globalização". Aliás, aquele vem a se contrapor, de certo modo, a este. O globalismo é uma palavra pejorativa e conspiratória (GLOBALISM, 2016) para designar o cosmopolitismo da Nova Ordem Mundial. A crítica não é à transnacionalização de capitais, mas à comunidade de valores internacionais incorporados, por exemplo, em declarações de Direitos Humanos, Civis e Políticos. Essa palavra "globalismo", usada por Buchanan na década de 1990, vem sendo reapropriada por Donald Trump, nos EUA (GLOBALISM, 2016), e por Ernesto Araújo, o ministro das Relações Exteriores de Bolsonaro (OLIVEIRA, 2019).

Do ponto de vista das quotas raciais, Buchanan a elas se opunha defendendo o princípio da "igualdade de todos perante a lei". O político via nas ações afirmativas artifícios discriminatórios que dividiam a América em duas categorias de cidadãos, em uma forma de racismo às avessas contra os brancos (BUCHANAN, 2003).

No que diz respeito ao tema da imigração, Buchanan era colunista da VDARE, uma publicação estadunidense conhecida por oferecer forte oposição a imigrantes e por defender teses do supremacismo branco (FRIZELL, 2016). Como forma de defender a cultura americana e ocidental, dizia ser preciso barrar o fluxo de imigrantes, apresentando estatísticas sem citar fontes, e considerando outras "raças", um termo vago, sem base científica, como inimigas da Civilização Ocidental:

Nos próximos 50 anos, o Terceiro Mundo terá crescido o equivalente a 30 ou 40 novos Méxicos. No final do século a população branca representará somente 3\%. Isso é o que eu chamo de morte do Ocidente. Eu vejo as nações morrerem quando as populações morrem. Eu vejo a civilização morrer. Estamos no momento sob ataque (BUCHANAN, 2002 , § 7, tradução nossa²).

\footnotetext{
${ }^{2}$ In the next 50 years, the Third World will grow by the equivalent of 30 to 40 new Mexicos. If you go to the end of the century, the white and European population is down to about three percent. This is what I call the death of the West. I see the nations dying when the populations die. I see the civilization dying. It is under attack in our own countries, from our own people.
} 
Quanto à pauta do meio ambiente, Buchanan afirmava ser inconstitucional proteger habitats naturais infringindo a propriedade privada de fazendeiros. Por meio de teorias conspiratórias, ele afirmava que era preciso defender os interesses nacionais frente à ditatura do "globalismo", que faz uso dos tratados internacionais para regular as indústrias e violar os Direitos de Propriedade com o argumento da preservação ambiental (ENVIRONMENTALISM, 2000).

Sobre o problema da Educação Nacional, a retórica empreendida por Buchanan lembra aquela do Movimento Escola Sem Partido (MESP) no Brasil. Para o republicano, as crianças nos EUA estariam a ter suas inocências roubadas, com suas mentes "envenenadas" contra a herança judaico-cristã, contra os heróis e a história da América. Os estudantes estariam sofrendo um processo de doutrinação ideológica em proveito do relativismo moral e da propaganda antiocidente (BUCHANAN, 1995). Além do mais, para o político, o darwinismo seria uma "teoria desastrosa", que, para ele, não seria científica, mas um dogma ideológico:

Crentes dogmáticos em evolucionismo têm dificuldade para reivindicar a sua doutrina como uma verdade estabelecida e cientificamente provada [...]. Os pais deveriam ter o direito de não terem suas crianças doutrinadas por um sistema de crença não comprovada, com a justificativa de não terem suas crenças tradicionais destruídas (BUCHANAN, 2005, § § 3 e 15, tradução nossa ${ }^{3}$ ).

Buchanan acreditava ainda que a vida começava desde a concepção e, por isso, condenava o aborto, dizendo que não importavam as circunstâncias para que fosse proibido. "Se alguém quiser executar outro por causa de um estupro, que execute o estuprador e deixe a criança nascer", afirmava (BUCHANAN, 1995b).

\footnotetext{
${ }^{3}$ Dogmatic believers in evolution are facing challenges to the claim that their doctrine is established truth, scientifically proven [...]. Parents have a right not to have their children indoctrinated in an unproven belief system, one purpose of which is to destroy their faith.
} 
Sobre os homossexuais, Buchanan afirmava, referindo-se à AIDS, que os gays "declararam uma guerra contra a natureza, e agora a natureza se volta contra eles":

Nossa sociedade está submersa em mentiras - a mentira de que a homossexualidade é natural, normal e com um estilo de vida saudável; a mentira de que aqueles que pensam diferente são intolerantes odiosos; a mentira de que doenças que afligem a comunidade homossexual são culpa de uma sociedade indiferente (BUCHANAN, 2006 , § 18, tradução nossa ${ }^{4}$ ).

Acusado pela mídia de deflagrar uma guerra cultural nos EUA, Buchanan culpava a esquerda radical por querer extirpar as tradições cristãs da sociedade:

Quem está diante de você aqui? Quem começou essa história? Quem é o ofensor? Quem disparou o gatilho? A resposta é óbvia. A esquerda radical ajudada pela elite cultural, que detesta a cristandade e pensa que os defensores da moral cristã são reacionários e repressivos, está determinada a impor seus valores morais e sua ideologia em nossa nação (BUCHANAN, 2004, § 9, tradução nossa ${ }^{5}$ ).

Como se vê, do ponto de vista da linguagem, a Retórica da Guerra Cultural parece ser aquela que, de certo modo, procura anular a leitura de mundo adversária, apagar da sociedade os valores que ela carrega, silenciar as vozes que defendem suas razões e introduzir outros elementos relacionados à sua própria pauta ideológica. É o que será visto no tópico seguinte.

\footnotetext{
${ }^{4}$ Our society is being marinated in lies - the lie that homosexuality is a natural, normal and healthy lifestyle; the lie that those who think otherwise are all hateful bigots; the lie that the diseases that afflict the homosexual community are the fault of an uncaring society.

${ }^{5}$ Who is in your face here? Who started this? Who is on the offensive? Who is pushing the envelope? The answer is obvious. A radical Left aided by a cultural elite that detests Christianity and finds Christian moral tenets reactionary and repressive is hell-bent on pushing its amoral values and imposing its ideology on our nation.
} 


\title{
3 A linguagem da Retórica da Guerra Cultural
}

Conceitos das ciências da linguagem que auxiliam a compreensão desse fenômeno são o de formação discursiva, interincompreensão constitutiva, diálogo de surdos, dicotomização, entre outros. O conceito de formação discursiva, tal como concebido por Foucault (2002) e apropriado por linguistas, pode ser compreendido se investigado o contexto de surgimento dessa noção quando do advento da Análise do Discurso dita francesa (AD) nas décadas de 1960 e 1970. Tratou-se de uma época em que alguns teóricos como Pêcheux e Althusser, na França, viram a necessidade de supressão das deficiências de uma análise de texto meramente de conteúdo até então em voga nas ciências humanas em geral (MAINGUENEAU, 1991). A Análise de Conteúdo se baseava essencialmente na quantificação de fenômenos recorrentes contidos no corpus, de modo a demonstrar suas principais constantes. De acordo com Pêcheux,

\begin{abstract}
Estudar uma língua era, na maior parte das vezes, estudar textos, e colocar a seu respeito questões de natureza variada provenientes, ao mesmo tempo, da prática escolar que ainda é chamada de compreensão de texto, e da atividade do gramático sob modalidades normativas ou descritivas [...]. As questões concernentes aos usos semânticos e sintáticos colocados em evidência pelo texto ajudavam a responder às questões que diziam respeito ao sentido do texto (o que o autor quis dizer) (PÊCHEUX, 1997, p. 61).
\end{abstract}

Trata-se, portanto, a Análise de Conteúdo, de uma concepção de texto encarando-o como se fosse algo estático e transparente. A AD vem justamente contestar essa ideia de imutabilidade e transparência do texto, postulando que o interpretar significa analisar os modos de funcionamento dos discursos na sociedade. A análise deixa então de ser um simples instrumento para as ciências sociais para se firmar em um ramo do conhecimento próprio à análise discursiva. 
Esse rompimento da $\mathrm{AD}$ em relação a uma prática escolar de Análise de Conteúdo, já sedimentada, deu-se provavelmente muito em função do contexto intelectual da época, marcado que estava, na era pós-maio de 1968 (um movimento progressista), pelo neomarxismo de Althusser, bem como pela Psicanálise lacaniana.

A leitura que Althusser (1998) realizou sobre a obra de Marx em Aparelhos Ideológicos do Estado colocava ênfase no aspecto da ideologia, e não nas condições materiais de produção, invertendo, portanto, o polo de determinações do materialismo histórico da tradição marxista. Se, em Marx, seriam as condições econômicas (infraestrutura) que engendrariam a ideologia, para Althusser, talvez em uma síntese com a filosofia hegeliana, bem como com a incorporação de pressupostos estabelecidos por Max Weber, seria a superestrutura (isto é, a ideologia em sua manifestação na cultura, no Direito, na escola, nos presídios, na família etc.) que determinaria as condições materiais (ALTHUSSER, 1998).

Pêcheux, considerado o fundador da $\mathrm{AD}$, teve em Althusser uma forte influência. Foi após tê-lo encontrado que teria entrado para a política (MALDIDIER, 2003). Um exemplo é o conceito de "formação ideológica" em Pêcheux, derivado da concepção de ideologia preconizada por Althusser. A ideia de "sujeito assujeitado" é tributária daquilo que Althusser chamou de "interpelação ideológica" no sujeito.

Outra influência de Pêcheux foi a Psicanálise lacaniana, com a ideia de um sujeito cindido pelo inconsciente, categoria herdada de Freud. O sujeito passou então a ser visto como influenciado por forças que não pode controlar. O consciente, representado pelo ego e pelo superego, seria somente a ponta do iceberg do psiquismo humano, dominado que é essencialmente pelo id, sua parte inconsciente (REALE, 2005b).

Entretanto, foi de Foucault que Pêcheux (1975) se apropriou do termo "formação discursiva", associando-o ao conceito de ideologia em Althusser e de 
assujeitamento da Psicanálise. Em Arqueologia do Saber, Foucault aborda essa ideia de formação discursiva da seguinte forma:

No caso em que se puder descrever, entre um certo número de enunciados, semelhante sistema de dispersão, e, no caso em que entre os objetos, os tipos de enunciação, os conceitos, as escolhas temáticas, se puderem definir uma regularidade (uma ordem, correlações, posições e funcionamentos, transformações), diremos, por convenção, que se trata de uma formação discursiva [...]. [Trata-se de] um conjunto de regras anônimas, históricas, sempre determinadas no tempo e no espaço, que definiram, em dada época, e para uma área social, econômica, geográfica ou linguística dada, as condições de exercício da função enunciativa (FOUCAULT, 2012, p. 43-44, 136).

Nesse sentido, o conceito de discurso, em Foucault, estaria atrelado a um sistema de formação que o conforma e estabelece seus modos de funcionamento, seu tom, seu léxico, seus temas, enfim, imprime uma série de regularidades próprias de um tipo específico de discurso. Este se define, com efeito, como o conjunto de enunciados ancorados em formações discursivas. Da mesma forma que uma frase está contida em um texto, um enunciado estaria envolto por uma formação discursiva, que estipula o que deve ou não ser dito, a depender da orientação cultural do contexto enunciativo.

Essa noção de formação discursiva auxilia a pensar na Retórica da Guerra Cultural (RGC), uma vez que esta se caracteriza por uma polarização exacerbada, em que um sujeito tende a não conseguir transcender as determinações de sua bolha ideológica, repetindo bordões que lhe são típicos. Por exemplo, é pouco provável um sujeito interpelado por uma formação discursiva progressista e de esquerda falar, no contexto brasileiro, em "marxismo cultural", "doutrinação ideológica nas escolas" ou "basta de Paulo Freire". O contrário também seria difícil de observar, isto é, um conservador de direita fazer a defesa do aborto ou do casamento igualitário, em cenário de guerra cultural. 
Não que, nesse caso, os discursos sejam absolutamente monológicos, maniqueístas e avessos ao dialogismo. Trata-se de uma questão de grau. Na RGC, o nível de polarização tende ao extremismo, e as formações discursivas se mostram mais unifocais. Como observa Maingueneau,

A distinção entre unifocal e plurifocal faz lembrar a oposição que Bakhtin estabelece entre textos "monológicos" e "dialógicos", que ele exemplifica com romances de Dostoievski: os primeiros são unificados pelo ponto de vista soberano do narrador; os outros mantêm uma irredutível pluralidade de pontos de vista (MAINGUENEAU, 2015, p. 92).

Entretanto, ainda que o apagamento do outro seja uma constante na RGC, mesmo um discurso que se pretende absoluto trará as marcas de seu adversário, levando-se em consideração que o dialogismo é constitutivo da linguagem (BAKHTIN, 1992). Por exemplo, quando Buchanan diz que relações homoafetivas não são naturais, ele traz a lume necessariamente o discurso ao qual se contrapõe, o que afirma que o desejo homossexual está presente na natureza. $\mathrm{O}$ monologismo aqui, ao qual Maingueneau se refere, diz respeito mais a uma intencionalidade, a uma visada de monologismo, uma tentativa de silenciar a voz adversária, que não se confunde com a intenção psicológica do autor, mas que se pode inferir do discurso através de uma materialidade textual.

Em outra obra, Maingueneau (2008) lança mão do termo “interincompreensão constitutiva" para designar esse fenômeno, esse apagamento da alteridade, contraditoriamente, evocando-a sub-repticiamente. É a impossibilidade de um polo da disputa pela verdade enxergar o outro pelas grelhas semânticas que não sejam as suas próprias, a incapacidade de se descentrar e entender os pressupostos, as categorias epistemológicas das quais o campo adversário se utiliza: 
Cada um introduz o Outro em seu fechamento, traduzindo seus enunciados nas categorias do Mesmo e, assim, sua relação com esse Outro se dá sempre sob a forma do "simulacro" que dele constrói. Nesse quadro, a relação polêmica, no sentido mais amplo, longe de ser o reencontro acidental de dois discursos que se teriam instituído independentemente um do outro, é de fato a manifestação de uma incompatibilidade radical, a mesma que permitiu a constituição do discurso (MAINGUENEAU, 2008, p. 21).

Marc Angenot (2008) qualifica essa interincompreensão típica da RGC como sendo um "diálogo de surdos". Em uma visão pessimista da argumentação, o autor afirma que o que se passa mais comumente nos embates retóricos é o fato de uma parte não ser capaz de escutar as razões de seu interlocutor, não saber se colocar no lugar dele. Por ignorar uma série de regras do debate e da argumentação, com vistas à imposição da verdade, o sujeito tenderia a se fechar em seus pressupostos, fazendo com que sejam raras as hipóteses de acordo, situação que pode perdurar por gerações:

Parece-me que os diálogos de surdos são, na vida social, a regra mais do que a exceção e que os mal-entendidos de ideias e as controvérsias perpétuas resultam frequentemente de discordâncias entre "famílias de espíritos", discordâncias quanto à maneira de abordar o mundo, de extrair e de produzir, a partir dele, sentidos antes de se chegar a convicções. Alguns desses diálogos de surdos, na vida pública, notadamente nas lutas políticas, podem se sustentar por um tempo correspondente a uma geração inteira (ou de várias), o problema estando normalmente regido pela desaparição dos adversários em presença e pela emergência de uma nova geração que não compreende mais o sentido das questões que tanto acaloraram e dividiram, nem tampouco os jogos de enfrentamento - a questão de saber quem, afinal de contas, "tinha razão", remetendo à insignificância, já que os jogos não menos que os termos mesmos dos quais os adversários se utilizavam para se confrontarem e se refutarem se tornaram igualmente obsoletos e desvalorizados (ANGENOT, 2008, p. 16, tradução nossa ${ }^{6}$.

\footnotetext{
${ }^{6} \mathrm{Il}$ me paraît bien que les dialogues de sourds soient, dans la vie sociale, la règle plutôt que l'exception et que les malentendus d'idées et les controverses perpétuelles résultent souvent de discordances entre "familles d'esprits", discordances quant à la façon d'aborder le monde, d'y déceler et d'y produire du
} 
Alguns traços descritos por Angenot correspondentes ao "diálogo de surdos" poderiam ser aplicados à RGC. Isso porque, em última instância, a postura de não escuta das razões alheias parece ser, ao mesmo tempo, causa e consequência da guerra cultural.

Segundo Angenot (2008), tudo enseja o fechamento diante do que o outro tem a dizer, a começar mesmo pelo estilo do discurso empregado. De fato, dependendo da abordagem que se faça ao interlocutor, este pode reagir de maneira adversa ou amigável. A Retórica aristotélica já ensinava que a arte de persuadir correspondia à arte de agradar. É o que Angenot (2008) denomina de grau superficial das divergências possíveis.

Apesar de não se tratar de mecanismos afeitos a raciocínios propriamente ditos, o estilo com que o enunciador se dirige ao auditório constitui já uma estratégia persuasiva, ensejando ou não a abertura a uma argumentação adulta no espaço público. Nas palavras de Angenot:

Convém, parece-me, descrever [...] uma forma fraca do desentendimento no qual o desacordo entre os indivíduos, a decodificação errônea da mensagem não diz respeito aos raciocínios propriamente ditos, mas a maneirismos da expressão [...]. Em outras palavras, tudo pode ruir desde o nível do estilo comunicacional, porque se trata de abordar o outro, de o colocar em estado de recepção [...] antes de argumentar [...] (ANGENOT, 2008, p. 131, negritos nossos, tradução nossa ${ }^{7}$ ).

sens avant d'aboutir à des convictions. Certains de ces dialogues de sourds, dans la vie publique, dans les luttes politiques notamment, peuvent se soutenir le temps d'une génération (ou de plusieurs), le problème étant ordinairement réglé par la disparition des adversaires en présence e par l'émergence d'une nouvelle génération qui ne comprend même plus le sens des questions qui ont tant passionné et divisé, ni les enjeux de l'affrontement - la question de savoir qui, au bout du compte, "avait raison" étant renvoyée à l'insignifiance puisque les enjeux non moins que les termes mêmes dont les adversaires se sont servi pour s'affronter et se réfuter sont également devenus obsolètes et dévalués.

${ }^{7} \mathrm{Il}$ convient, il me semble, de décrire d'abord une forme faible du malentendu où le désaccord entre les individus, le mauvais déchiffrement du message ne tiennent pas aux raisonnements proprement dits, mais à des maniérismes de l'expression [...]. Autrement dit, tout peut casser dès le stade du style communicationnel, car il s'agit d'aborder l'autre, de le mettre en état de réception [...] avant d'argumenter. 
Essas estratégias são, portanto, consideradas pré-argumentativas se a palavra "argumentação" for entendida em um sentido estrito, referindo-se aos raciocínios argumentativos. Entretanto, em uma perspectiva pan-argumentativista, tal como a esboçada por Amossy (2006), por exemplo, que, por meio do conceito de "dimensão argumentativa", defende que é da constituição da linguagem a intencionalidade de exercer algum tipo de influência sobre o outro, pode-se dizer tratar-se também de uma estratégia argumentativa o estilo com o qual se aborda o interlocutor. É nesse sentido que se fala, assim, em estilo da argumentação, entendendo esta em sentido amplo, englobando outros aspectos além dos estritamente lógicos.

Associado a esse problema do estilo do discurso, releva a questão da violência verbal, que tende a aparecer nos confrontos culturais mais acalorados. Para Maingueneau, “a violência verbal é [...] uma noção intuitiva difícil de traduzir em termos linguísticos" (MAINGUENEAU, 2008, p. 113), apesar de percebida na materialidade textual. Segundo Amossy (2014), a violência verbal não é um traço essencial das relações polêmicas. No entanto, em situação de diálogo de surdos da guerra cultural, a violência tende a ser uma constante. Eis um exemplo extraído do Twitter, no contexto do debate público em torno do vazamento pelo jornal The Intercept (GREENWALD, 2019) de conversas entre o então juiz da Lava-Jato Sérgio Moro, posteriormente Ministro da Justiça de Bolsonaro (antes de pedir demissão em abril de 2020), responsável na época pela condenação do ex-presidente Lula em primeira instância, e o procurador Deltan Dallagnol.

As mensagens indicaram um suposto acordo entre o juiz e a acusação para combinar a ordem do processo, pulando etapas e acertando os meios de prova. A postagem a seguir da jornalista da Folha de S. Paulo, Mônica Bergamo, deu-se nesse contexto do vazamento, mas não se refere ao assunto especificamente. Trata-se de notícia sobre a tramitação de um Habeas Corpus no STF para beneficiar Lula por ter sido preso automaticamente após decisão de segunda instância. Preferiu-se aqui 
reproduzir a situação real de comunicação das interações no Twitter, com um print da postagem, desfocando os nomes e os rostos nos comentários:

Imagem 1 - Guerra cultural no Twitter.

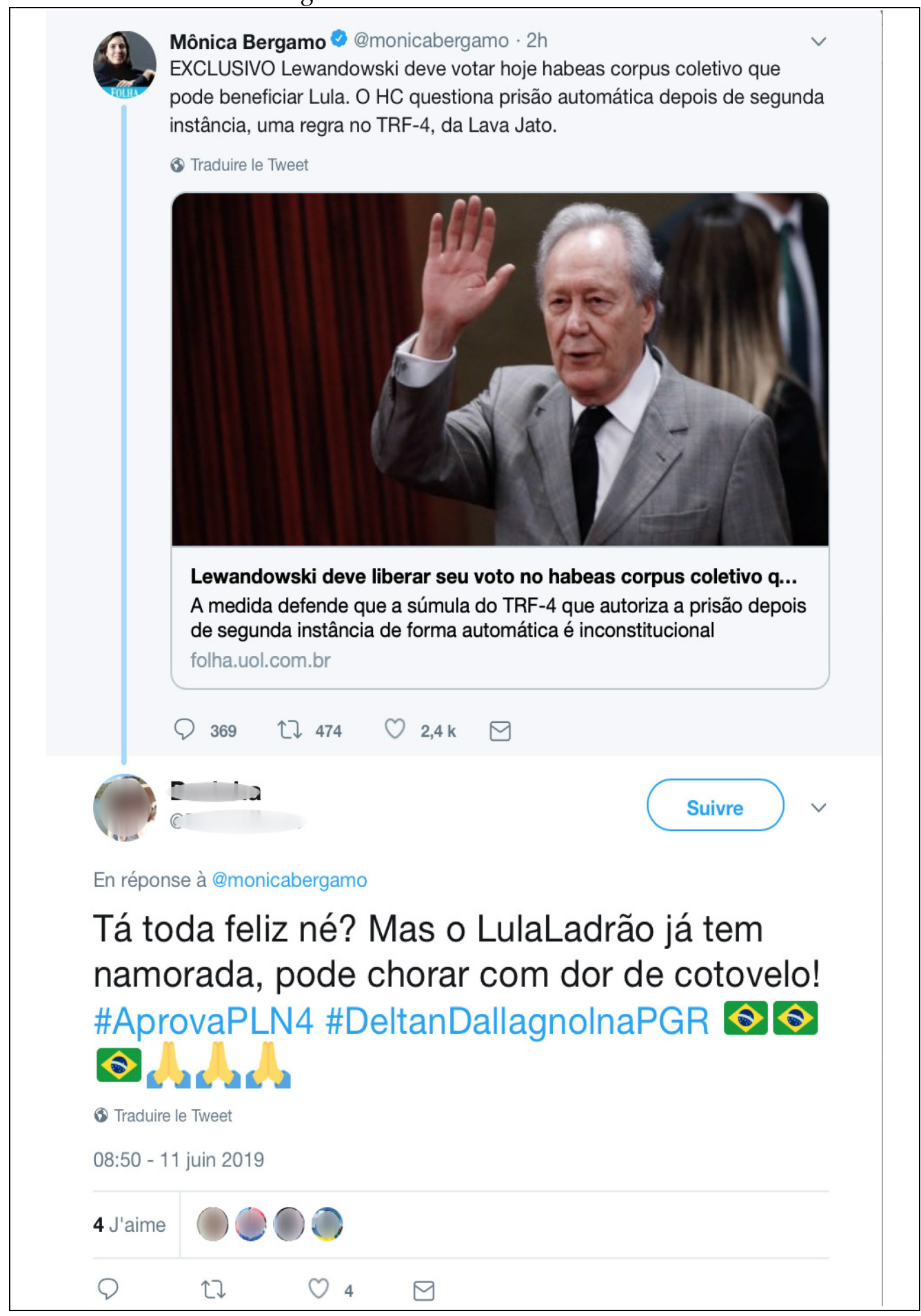

Fonte: Twitter $^{8}$.

${ }^{8}$ Disponível em: https://twitter.com/monicabergamo. Acesso em: 11 jun. 2019. 
Aqui não se trata de um conflito explicitamente cultural. O debate não gira em torno de pautas específicas de campos ideológicos opostos, mas se refere a uma questão técnica jurídica, sobre a concessão de Habeas Corpus ao ex-presidente Lula. No entanto, a interação entre a postagem de Mônica Bergamo e o comentário faz transparecer uma guerra cultural de fundo que se estabelece no debate público, notadamente nesse período de exacerbação dos ânimos correspondente ao vazamento de conversas entre o juiz Moro e o procurador Dallagnol sobre a condenação de Lula.

$\mathrm{O}$ fato de a comentarista (trata-se de uma mulher) da postagem se colocar no debate com bordões manifestados por meio de hashtags como \#AprovaPLN4 e \#DeltanDallagnoPGR, nesse contexto específico, sem relação com a referida postagem, tende a circunscrever essa comentarista em um campo da direita conservadora. A postagem de Mônica Bergamo não faz referência ao Projeto de Lei do Congresso Nacional n. 4 (PLN 4). A comentarista, ao introduzir esse debate, mostra que não importa o que está sendo veiculado pela jornalista, e sim a causa de seu campo cultural, que consiste em aprovar automaticamente tudo que venha da família Bolsonaro. $\mathrm{O}$ presidente e seus filhos (um senador, um deputado e outro vereador) estavam, no momento, provavelmente em uma tentativa de silenciar a discussão sobre a polêmica em relação ao seu ministro da Justiça, Sérgio Moro, bastante popular entre a direita, lançando uma forte campanha nas redes sociais para aprovação desse projeto de lei para concessão de crédito suplementar de 248 bilhões no orçamento do governo (BOLSONARO DIZ, 2019).

O mesmo se pode dizer sobre o apoio a Deltan Dallagnol pela comentarista. A reportagem de Mônica Bergamo não faz referência ao procurador, mas o contexto era de exacerbada polêmica pública sobre os vazamentos mencionados pelo periódico The Intercept. Assim, em sua mensagem, a comentarista, em situação de guerra cultural, não poderia se furtar de deixar as marcas de seu posicionamento incontinenti ao 
governo e às estruturas que permitiram a condenação do ex-presidente do Partido dos Trabalhadores (PT) Lula da Silva.

Vê-se, portanto, que, em face de uma reportagem que sugere a hipótese de algum benefício ao ex-presidente, a comentarista demarca o seu território de batalha, ensurdecida para a mensagem que Mônica Bergamo possa veicular, e adotando um estilo violento que impossibilita toda forma de conciliação, ameaçando a face da jornalista, ao conjecturar sobre sua sexualidade/intimidade/afetividade pelo simples fato de realizar uma cobertura jornalística sobre um político (“Está toda feliz né? Mas o LulaLadrão já tem namorada, pode chorar com dor de cotovelo").

Para a Teoria das Faces de Brown e Levinson (1997), inspirada na obra de Goffman (1974), uma vez que a comunicação verbal se estabelece no interior de relações sociais, ela se submete a algumas leis para que haja possibilidade de debate. O mero fato de se dirigir a palavra a alguém, monopolizando a atenção, fugindo do assunto etc., já seria uma forma de intrusão na esfera subjetiva alheia. No modelo da teoria das faces, todo indivíduo possuiria: a) uma face negativa, correspondente ao "território" de cada um (corpo, intimidade etc.); b) uma face positiva, a fachada social, aquilo como o sujeito quer ser visto no mundo. Na leitura de Andrade \& Fávero,

[...] a face negativa é o desejo de liberdade de ação e o domínio do conjunto dos territórios do eu, e a positiva, o desejo de ser aceito pelos outros e de que estes compartilhem os mesmos desejos (ANDRADE; FÁVERO, 2015, p. 106).

No caso em questão, há ameaça, pela comentarista, à face de Mônica Bergamo, na medida em que se levantam contra a jornalista elementos relativos ao seu foro íntimo, bem como sua imagem social enquanto jornalista. $\mathrm{O}$ argumento implícito desse estilo violento de abordagem é aquele considerado machista, segundo o qual, para que uma mulher se interesse por apurar fatos de um político, ela precisa estar apaixonada, afetada por ele. Na mesma época, no mesmo contexto de polêmica pública sobre os 
vazamentos de atores da Lava-Jato, o radialista e apresentador da RedeTV Emílio Surita havia dito que Mônica Bergamo devia ter uma tatuagem de Lula na virilha (EMÍLIO SURITA, 2019).

Além de regras do estilo (como se viu pela comentarista do tweet de Mônica Bergamo ter se desviado do assunto), houve, segundo Angenot (2008), uma infração do que o autor denomina de regras do suporte. Este termo não é empregado por Angenot no sentido mais usual de condições materiais de veiculação do discurso, mas de condições do contrato de comunicação estabelecido entre os interlocutores, as chamadas esquematizações. Nas palavras de Angenot,

A esquematização [...] delimita uma situação colocada em debate; ela lhe fixa limites de pertinência que serão os limites da discussão, que impedirão de se "voltar ao tempo do Dilúvio" e de "sair do assunto". Não é suficiente que um argumento seja razoável, é preciso ainda que ele "tenha a ver" com a questão constituída. Os sociólogos americanos falam de "frames", designando assim o "enquadramento" dentro do qual se fecham os dados relevantes e as "perspectivas" sobre as quais se escolhem apresentar (ANGENOT, 2008, p. 149, negrito nosso, tradução nossa ${ }^{9}$ ).

Apesar de ainda não formarem a argumentação, a manipulação dessas condições situacionais já pode constituir uma estratégia persuasiva (ANGENOT, 2008). O simples fato de selecionar o que se vai dizer, de mudar de assunto para panfletar uma fala coletiva própria de uma matriz ideológica parece ser uma constante na RGC.

\footnotetext{
${ }^{9}$ La schématisation [...] délimite une situation mise sous discussion; elle lui fixe des limites de pertinence qui seront des limites à la discussion, qui interdiront de « remonter au Déluge » et de " sortir du sujet». Il ne suffit pas qu'un argument soit raisonnable, il faut encore qu'il «ait à voir » avec la question ainsi constituée. Les sociologues américains parlent de "frames", désignant ainsi le « cadrage » dans lequel on enferme les données retenues et les « perspectives » sous lesquelles on choisit de les présenter.
} 
Outras causas de discórdia, além dessas regras referentes ao estilo e ao suporte, residem, para Angenot (2008), na infração de algumas regras do debate e de regras da argumentação. Estas seriam aquelas que estabelecem o que são argumentos válidos e inválidos, plausíveis ou inverossímeis, fortes ou fracos, pertinentes ou não, suficientes, necessários ou contingentes, coerentes ou absurdos, elementos que podem ser garantidos por provas que assegurariam a vitória de uma tese.

Do ponto de vista das regras da argumentação, caracteriza a RGC, ainda, a presença constante de argumentos ad personam ${ }^{10}$, aqueles que repousam nas qualidades do orador, para desqualificá-lo. Isso significa declarar, desde o início, que não se quer tocar no conteúdo ou no encadeamento lógico do discurso, mas colocar ênfase nos aspectos de quem o profere. Denunciar que o interlocutor pertence a determinado partido, que foi contra, no passado, a alguma causa em específico, que não possui autoridade/formação/experiência para discutir um assunto etc. são lugares típicos do argumento ad personam. No exemplo do Twitter acima (imagem 1), para se colocar em dúvida a palavra de Mônica Bergamo, a comentarista recorreu à afetividade da jornalista em relação à Lula.

Vanderford define o argumento ad personam como uma estratégia retórica que lança descrédito sobre o adversário, ressaltando-lhe o partidarismo ou a má-fé (VANDERFORD, 1989). Para Kerbrat-Orecchioni, o argumento ad personam é próprio de toda polêmica, uma vez que este é por definição um discurso desqualificador (KERBRAT-ORECCHIONI, 1990). Amossy, por sua vez, ressalta que toda sorte de artifícios retóricos pode ser usada para desqualificar o adversário, como a negação, a reformulação orientada, a ironia, a deformação dos propósitos etc. (AMOSSY, 2014). Na RGC, esse descrédito lançado sobre o adversário muitas vezes não se restringe a

\footnotetext{
${ }^{10}$ Adotou-se aqui a nomenclatura proposta por Angenot, para o qual o argumento ad personam é uma espécie de argumento ad hominem, quando se quer alegar as qualidades do orador para descredenciá-lo
} (ANGENOT, 2008, p. 202). 
ele, mas a todo o grupo ideológico ao qual pertence. É o caso do exemplo abaixo, ainda no mesmo contexto do vazamento de falas de autoridades da Lava-Jato:

Imagem 2 - Guerra cultural no Twitter.

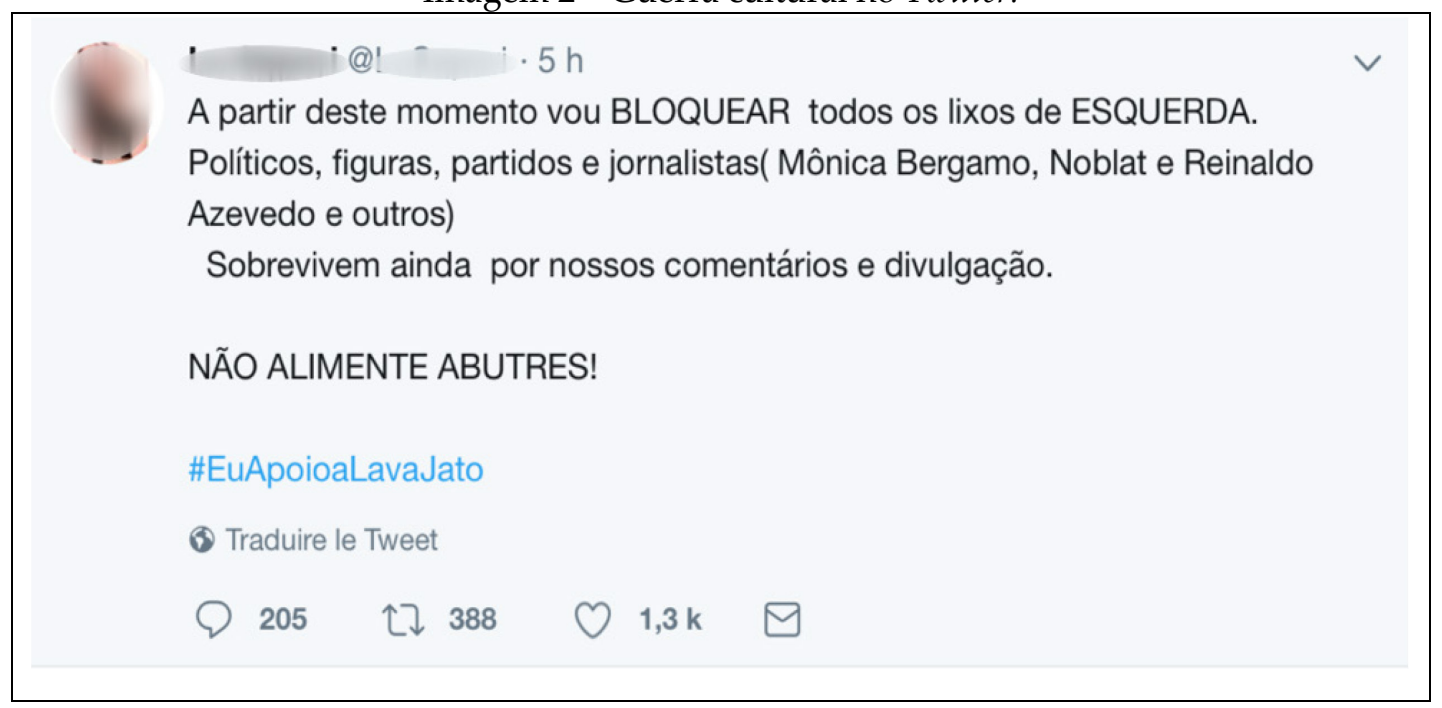

Fonte: Twitter ${ }^{11}$.

Essa postagem é o exemplo extremo da recusa ao diálogo, do ensurdecimento para as razões do outro. É a intransigência em seu ápice. Aqui, a autora do tweet, com o verbo "bloquear", busca interromper toda fonte de comunicação que possa vir do que ela chama de "esquerda", escrita em caixa alta (de "políticos, partidos, jornalistas"). Isso significa dizer que a comentarista desqualifica a priori toda informação, independentemente do que possa ser veiculado. O interesse não é a procura pelo esclarecimento de fatos, em busca de sua veracidade, mas eliminar do campo do possível aqueles que possam vir a incomodar suas crenças e preconceitos.

Curioso notar que os jornalistas mencionados (Mônica Bergamo, Noblat e Reinaldo Azevedo) são representantes do que se denomina por "grande mídia" ou "mídia tradicional", como Folha de S. Paulo e Veja, execrada igualmente muitas vezes

${ }^{11}$ Acesso em: 10 jun. 2019. 
por militantes do polo oposto da guerra cultural, a esquerda progressista, como se pode perceber abaixo:

Imagem 3 - Guerra cultural no Twitter.

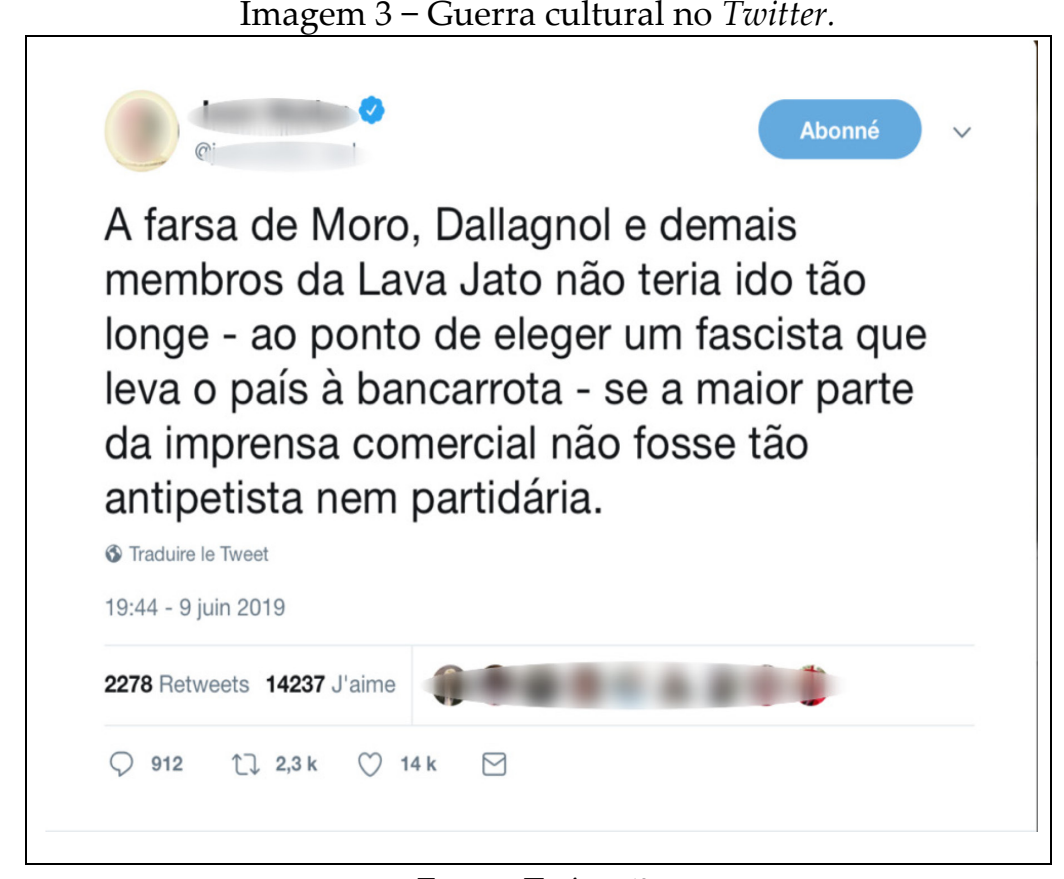

Fonte: Twitter ${ }^{12}$.

Aqui um ex-deputado do PSOL (Partido Socialismo e Liberdade) atribui ao que chama de "imprensa comercial", com seu antipetismo e partidarismo, a culpa pelo suposto conluio entre o juiz Moro e o procurador Dallagnol, e pela exaltação destes à categoria de heróis nacionais, no processo criminal do ex-presidente Lula.

Um outro traço da RGC seria o dogmatismo, também conhecido como "espírito de ortodoxia". É a disposição do sujeito, segundo Angenot (2008), que leva, no interior de um sistema de crenças, a objetar a priori toda afirmação que possa vir a contradizer alguns pressupostos. Questionar esse sistema de crenças é ameaçá-lo, constituindo uma declaração de guerra, sejam lá quais forem os argumentos e o modo de apresentação dos mesmos. Nas palavras de Angenot,

\footnotetext{
12 Acesso em: 15 jun. 2019.
} 
O dispositivo dogmático filtra a informação de maneira através da qual toda consideração só serve para reforçar as certezas pré-estabelecidas, o que demonstra uma resistência ilimitada ao questionamento de seus dogmas (ANGENOT, 2008, p. 307, tradução nossa ${ }^{13}$ ).

Trata-se de uma espécie de imunização retórica, um dispositivo de perseverança próprio da luta entre direita conservadora e esquerda progressista ${ }^{14}$; uma ideologia política formando um discurso que se institui e se perpetua pela fé imposta aos militantes sem necessidade de aprofundamento das razões adversárias. A aceitação e a legitimidade de certas ideias, assim, encontram eco no próprio discurso em que foram engendrados, sem rigor quanto à objetividade das provas.

Os dois últimos exemplos (imagens 2 e 3) são casos de manifestação desse dogmatismo próprio da RGC. O primeiro, como se viu, busca uma objeção a priori de todo argumento proveniente do campo cultural oposto, além de deixar explícita a afirmação categórica segundo a qual "todos são abutres", referindo-se aos adversários do outro lado da batalha. O segundo exemplo procura estabelecer uma relação causal e necessária entre antipetismo e partidarismo de um conjunto majoritário da chamada "imprensa comercial" e a suposta "farsa" de Moro e Dallagnol, bem como a eleição do então presidente da República Jair Bolsonaro. Esses propósitos sugerem afirmações gerais e categóricas como: "a maior parte da imprensa comercial é antipetista"; "a maioria da imprensa comercial é partidária”; "a imprensa comercial de modo geral é culpada pela eleição de Bolsonaro"; “a imprensa comercial é causa da 'farsa' de Moro e Dallagnol terem ido tão longe"; "Bolsonaro é fascista" etc.

\footnotetext{
${ }^{13}$ Le dispositif dogmatique filtre l'information de manière à travers laquelle tout ce qui est pris en considération renforce les certitudes premières et dispose d'une résistance illimitée à la mise en cause de ses dogmes.

14 Tomando como parâmetro a teorização de Charaudeau (2016), a matriz ideológica do discurso político de esquerda apresenta uma tendência progressista, ao passo que a matriz de direita, uma tendência conservadora.
} 
Corolário desse dogmatismo é o pensamento maniqueísta próprio da RGC. Esse maniqueísmo baseia-se em uma lógica de raciocínio binário que tende a colocar um campo cultural no domínio do mal em si, do mal ontológico, e outro campo, o do próprio do falante, na categoria do bem absoluto. Nesse tipo de enunciação, é frequente o uso de elementos do discurso religioso para figurativizar a divisão entre dois mundos inconciliáveis. De acordo com Angenot, "toda ideologia privilegia as oposições axiológicas binárias na medida em que ela tende a formar uma sociomaquia binária narrando uma disputa entre dois princípios, um bom e outro mau [...]" (ANGENOT, 2008, p. 310, tradução nossa ${ }^{15}$ ). Eis um exemplo:

Imagem 4 - Maniqueísmo na guerra cultural.

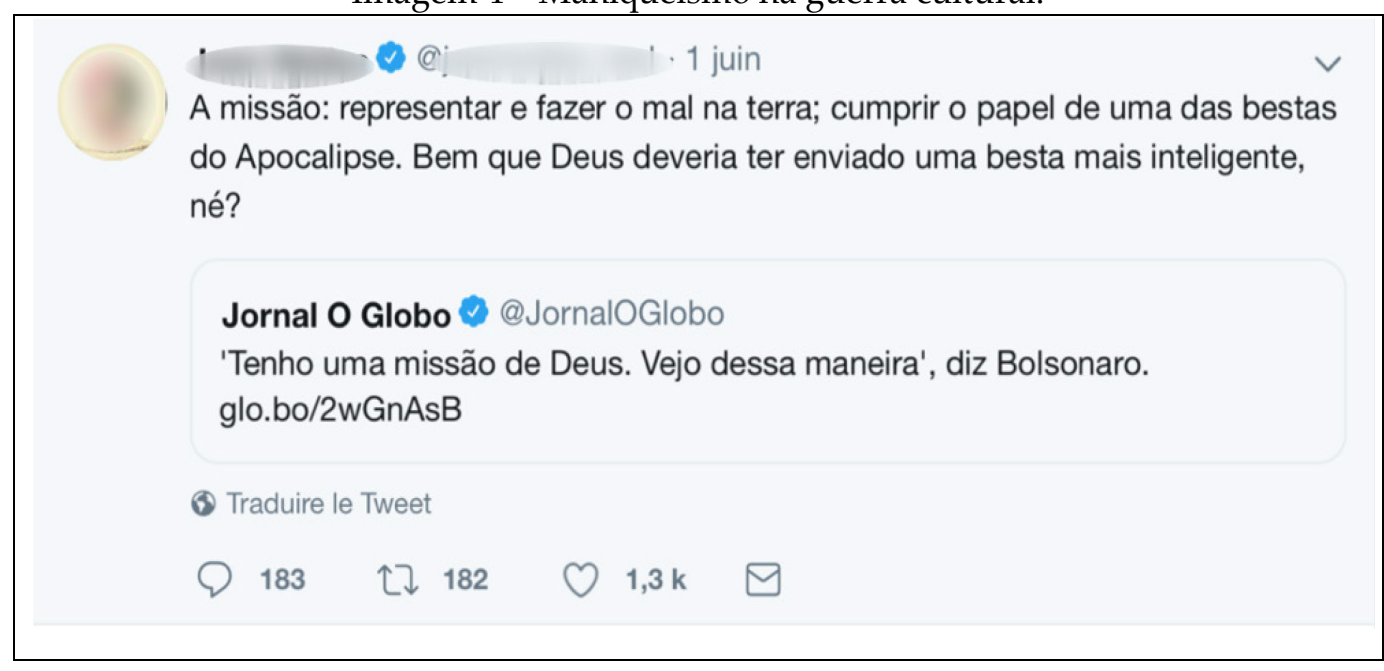

Fonte: Twitter ${ }^{16}$.

$\mathrm{Na}$ postagem de Twitter acima, percebe-se a estrutura de pensamento maniqueísta nos dois lados da guerra cultural. Ao passo que o presidente Bolsonaro se autoproclama como um messias enviado de Deus para combater o mal na Terra, o mesmo ex-deputado do PSOL mencionado no exemplo anterior questiona esse

\footnotetext{
15 Toute idéologie privilégie les oppositions et axiologies binaires dans la mesure où elle tend à former une sociomachie, dans la mesure où elle narre la lutte entre deux principes, un bon et un mauvais.

${ }^{16}$ Acesso em: 10 jun. 2019.
} 
estatuto, defendendo o contrário, que a missão do presidente seria a de representar o demônio. A cena religiosa se inscreve aqui no discurso pelo léxico, com termos como "missão de Deus" e "bestas do apocalipse", uma figura bíblica do livro Apocalipse do apóstolo João que representa o Anticristo.

Amossy (2014) prefere chamar esse maniqueísmo entre dois polos da guerra cultural de dicotomização, que ela diferencia da mera polarização (AMOSSY, 2014). Para a autora, é da natureza da polêmica ser conflitual, separar dois campos distintos da argumentação em torno de determinado assunto, configurando a polarização. Mas, quando o conflito se torna extremo e insolúvel, transcendendo a simples divergência entre indivíduos em relação a um assunto qualquer e demarcando polos ideológicos opostos, aí a divergência é entre grupos, e não mais entre indivíduos, descambando para a dicotomização. Nas palavras de Amossy,

Construir as oposições como dicotomias, como pares de noções excludentes uma em relação à outra sem possibilidade de compromisso, consiste em bloquear toda possibilidade de solução e em fechar as partes em um face a face no qual elas defendem posições inconciliáveis [...]. [Já a] polarização se cria a despeito de diversas divergências [..]. De fato, os atores que endossam um papel de Propositor ou de Opositor podem se basear em argumentos diferentes; eles não participam necessariamente de um mesmo grupo social, e podem até se pronunciar em nome de ideologias diferentes (AMOSSY, 2014, p. 57-59, tradução nossa ${ }^{17}$ ).

Portanto, pode-se dizer que, na RGC, prevalece a dicotomização, mais do que a polarização, no sentido que Amossy confere a essas palavras. Isso porque a divergência em cenário de guerra cultural se estabelece a priori, por meio de ideologias

\footnotetext{
${ }^{17}$ Construire les oppositions comme des dichotomies, des paires de notions exclusives l'une de l'autre sans possibilité de compromis, consiste à bloquer toute possibilité de solution, et à enfermer les parties dans un face à face où elles campent sur de positions inconciliables [...]. [De son côté,] la polarisation se crée au-delà, et en dépit, de nombreuses divergences [...]. En effet, les acteurs qui endossent le rôle de Proposant ou d'Opposant peuvent se fonder sur des arguments différents; ils ne participent pas nécessairement du même groupe social, et peuvent même se prononcer au nom d'idéologies différentes.
} 
pré-existentes ao discurso, apesar de se manifestarem nele. Essa é uma noção que se relaciona, de certa forma, ao conceito de interincompreensão constitutiva entre duas formações discursivas antitéticas proposto por Maingueneau (1983), conforme visto acima.

Quanto às regras do debate, estas concernem ao próprio rito da interlocução, fixando restrições aos falantes para defenderem suas teses e articularem suas provas (ANGENOT, 2008). Uma dessas regras, para Angenot (2008), por exemplo, é o ônus da prova ${ }^{18}$. A infração dessas normas seria uma forma de corrupção procedimental. Nesse sentido, inculpar o adversário de algo sem oferecer prova e atribuindo-lhe a obrigação de provar sua inocência seria fator suficiente para o estabelecimento do diálogo de surdos, um traço típico da RGC. Nas palavras de Angenot:

As regras do debate fixam, portanto, as condições procedurais requeridas dos interlocutores para que eles aceitem o debate, condições que são concebidas como indispensáveis, fora das quais haverá frustração recíproca e impossibilidade de diálogo. Essas regras fixam em quais condições um debate pode se iniciar, quais serão as obrigações recíprocas dos interlocutores, o que arbitrará o turno de falas etc. Essas "regras do jogo" são sentidas como indispensáveis, sendo que a transgressão das mesmas indispõe os que se encontram em debate (ANGENOT, 2008, p. 133, tradução nossa ${ }^{19}$ ).

Poder-se-ia acrescentar a essas regras do debate propostas por Angenot as regras de cooperação ou máximas conversacionais estipuladas por Grice (1979), que teriam a mesma função ao legislarem sobre aquilo que permitiria ao diálogo ser

\footnotetext{
${ }^{18}$ Angenot inclui também, nas regras do debate, a observância aos turnos das falas nas interações. Como não se diz haver interação simultânea oral em postagens de redes sociais, o gênero sobre o qual se debruça neste artigo, esta parte das regras do debate não será analisada aqui.

${ }^{19}$ Les règles du débat fixent donc les conditions procédurales requises des interlocuteurs pour qu'ils acceptent de débattre, conditions qui sont conçues comme indispensables c'est-à-dire en dehors desquelles il ne peut y avoir que frustration réciproque et échec de la discussion. Elles fixent à quelles conditions un débat peut débuter et ce que seront les obligations réciproques des disputants, ce qui arbitrera leurs tours de parole etc. Ces «règles du jeu» sont senties comme indispensables, leur transgression indispose.
} 
considerado como sério e possível. São regras que não estão no enunciado, mas nas condições para a comunicação.

Uma dessas regras, em Grice, que corresponde à regra do debate do ônus da prova proposta por Angenot, é a regra da sinceridade. Trata-se do princípio segundo o qual os propósitos dos interlocutores se presumem verdadeiros. O falante, assim, deve ter condições de garantir a veracidade daquilo que profere. No exemplo citado na imagem 1, a comentarista da postagem de Mônica Bergamo infringe essa máxima da sinceridade, uma vez que responde à notícia sobre o julgamento do Habeas Corpus de Lula com assuntos como a sexualidade da jornalista, sem poder garantir a sua veracidade.

Danblon (2004) chama essa inversão do ônus da prova, ou, de acordo com Grice, a infração da regra da sinceridade, de "retórica da denunciação". Esta ocorre quando o locutor se desresponsabiliza por sua acusação, o que o torna passivo e infantilizado. Trata-se de uma retórica tradicionalmente utilizada por demagogos que buscam explorar a cólera e o medo dos mais frágeis e menos instruídos, segundo a autora (DANBLON, 2004).

Continua Danblon (2004), a demagogia institucionalizada pelo denuncismo irresponsável desvia o sentido da argumentação crítica das sociedades abertas. Isso porque quem julga precisa apresentar elementos novos para justificar sua condenação. Quem argumenta é quem tem o ônus da prova, o que significa que, nas regras do debate, quem critica é quem deve se esforçar para convencer, para persuadir o auditório, o contrário do que se passa com a retórica da denunciação (DANBLON, 2004). Nas palavras de Danblon,

A retórica da denunciação é a alternativa cínica e desabusada à retórica politicamente correta. Essas duas faces modernas da retórica são fundadas na mesma concepção de democracia. Coloca-se acento na proteção do cidadão mais que sobre sua responsabilidade e capacidade de ação. Diante do medo legítimo da manipulação, essas duas retóricas 
modernas oferecem uma resposta em termos de proteção de um cidadão passivo e infantilizado. Tais hábitos retóricos, aliás, sempre existiram. A retórica da denunciação foi tradicionalmente utilizada por oradores demagogos que deformam o julgamento crítico, transformando-o em suspeita generalizada, explorando a cólera e o medo dos mais frágeis e menos instruídos [...]. Como essa demagogia institucionalizada deturpa o senso crítico? [...]. Ora, quem julga precisa oferecer elementos novos, bem como justificar seus propósitos. Já que é quem argumenta, é dele o ônus da prova. Isso significa que, no jogo do debate, é de quem critica o esforço de convencer, de ganhar o assentimento de um auditório, o qual adere, a priori, às normas da sociedade. Ao contrário, a retórica da denunciação opera uma inversão do ônus da prova (DANBLON, 2004, p. 67-70, tradução nossa ${ }^{20}$ ).

Outro tipo de retórica em que se percebe a inversão do ônus da prova é a "retórica da conspiração", também conhecida como da "causalidade diabólica" (POLIAKOV, 1980). Nesse caso, observa-se igualmente uma retórica da denunciação, mas mais específica. Trata-se da denúncia de um suposto complô, representado pelo conluio de determinados setores da sociedade para exercer um projeto de poder (ANGENOT, 2008). Parte-se de uma série de eventos considerados desagradáveis e, com a pretensão de descobrir a causa de todo o mal, fornece-se um diagnóstico da realidade alimentando-se pelo ódio e pelo ressentimento de se ver em uma situação de inferioridade diante dos supostos dominadores. À sensação de se ver humilhado,

\footnotetext{
${ }^{20}$ La rhétorique de la dénonciation est l'alternative cynique et désabusée à la rhétorique politiquement correcte. Ces deux visages modernes de la rhétorique sont fondés sur la même conception de la démocratie. On met l'accent sur la protection du citoyen plutôt que sur sa responsabilité et sa capacité $\mathrm{d}$ 'action. Face à la peur légitime de la manipulation, ces deux rhétoriques modernes offrent une réponse en termes de protection d'un citoyen passif et infantilisé. De telles habitudes rhétoriques ont d'ailleurs toujours existé. La rhétorique de la dénonciation a été traditionnellement utilisée par des orateurs démagogues qui déforment le jugement critique en un soupçon généralisé, en exploitant la colère et la peur des plus fragiles et des moins instruits [...]. Comment cette démagogie institutionnalisée détournet-elle le sens de la critique ? [...] Or qui juge se doit d'apporter des éléments nouveaux et de justifier sa démarche. Puisque c'est lui qui argumente, c'est lui qui a la charge de la preuve. Cela signifie que, dans le jeu du débat, c'est celui qui critique qui doit faire l'effort de convaincre, de gagner l'assentiment d'un auditoire, lequel adhère a priori aux normes de la société. Il est frappant de constater que la rhétorique de la dénonciation opère un renversement de la charge de la preuve [...].
} 
ultrajado, rebaixado, oprimido, lesado, segue-se o prazer intelectual de ter descoberto a causa primeira, o mecanismo desencadeador de toda a usurpação social, mesmo que essa atribuição de causa não seja seguida da responsabilidade de fornecer prova para tal (ANGENOT, 2008).

Um clássico do conspiracionismo da RGC é a hipótese de complô da imprensa tradicional, como observado na imagem 3, em relação aos grandes projetos de poder na sociedade. Esse tipo de teoria da conspiração pode ser encontrado tanto em um discurso conservador, quanto progressista.

Os dois exemplos abaixo ilustram que, a partir de um mesmo fato, o atentado a Jair Bolsonaro em Juiz de Fora quando era candidato à presidência, pode inspirar conjecturas diversas:

Imagem 5 - Conspiração na guerra cultural.
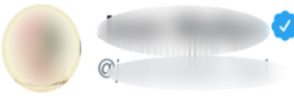

\section{Abonné}

Estranhíssima! Uma pena que investigações sérias não nos permitam saber quem pagou ou paga os advogados de Adélio, que, embora desempregado, teve dinheiro para pagar o mesmo clube de tiros frequentado pelos Bolsonaros.

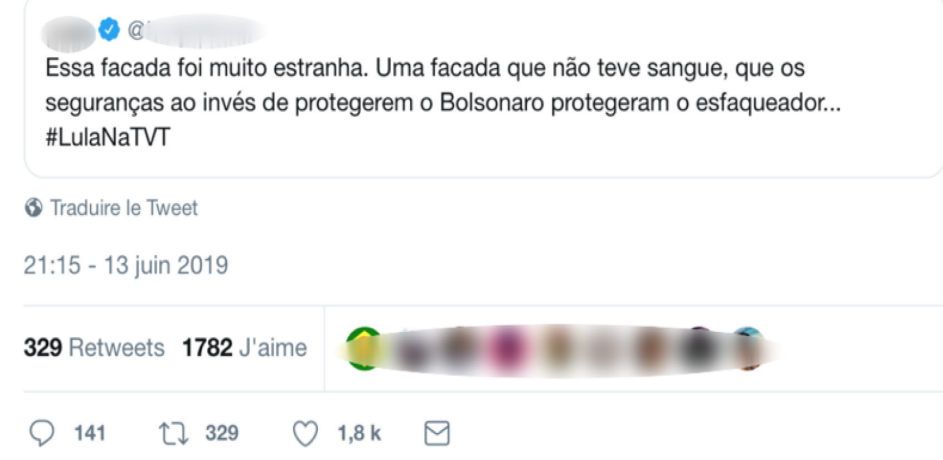

Fonte: Twitter ${ }^{21}$.

${ }^{21}$ Acesso em: 10 jun. 2019. 
Imagem 6 - Conspiração na guerra cultural.

May 28 at 11:05 AM $\cdot \ddot{\circ}$

Por que será que até hoje o presidente da Camara dos Deputados, o Botafogo, não informou quem registrou fraudulentamente a entrada de adelio bispo no congresso? É fácil descobrir. E quem ele foi visitar três vezes? Em qual gabinete? Para registrar quem entra é preciso informar $\mathrm{n}^{\circ}$ de documento, residência, etc.

Como o adelio conseguiu atestado de sanidade mental para frequentar clube de tiro?

Quem sustentava e pagava viagens, cartões de crédito, celulares, laptops, enfim, as despesas de adelio ? Quem pagou seus advogados caríssimos?

Advogado está acima da lei? Pode receber dinheiro de lavagem e do crime sem precisar prestar contas nem declarar quem pagou? Quem pagou o jatinho antes mesmo da notícia da autoria do atentado estar em todo o noticiário?

Duas pessoas que frequentaram a mesma pensão em Juiz de Fora já morreram. Coincidência?

O delegado que comandou a apuração em Minas era homem de confiança da dilma e foi condecorado em Ouro Preto no início do ano passado, meses antes do atentado, com a medalha de Tiradentes pelo então governador, o pimentel do PT. Homem de confiança da dilma, companheiro e ex-terrorista filiado ao grupo de guerrilha VAR-Palmares e um dos fundadores do PT. Coincidência?

Adelio Bispo era filiado até recentemente ao PSOL. Coincidência?

Só por curiosidade, as pesquisas no ano passado davam como inevitável a reeleição de pimentel como governador e a eleição de dilma, como senadora. Os dois perderam fragorosamente. Dá para acreditar em pesquisas no Brasil?

Quem mandou matar Jair Bolsonaro? Quem são os poderosos que impedem a apuração do atentado contra o Presidente da República? São muito poderosos mesmo.

\#QuemMandouMatarBolsonaro ?

$-1$

(1) 308

Fonte: Facebook ${ }^{22}$.

${ }^{22}$ Acesso em: 10 jun. 2019. 
No argumento do representante da esquerda progressista, o ex-deputado do PSOL, no primeiro exemplo (imagem 5), pergunta quem estaria pagando os advogados de Adélio Bispo, autor do crime e desempregado, bem como o fato de este ter participado de um clube de tiros frequentado pelos Bolsonaro como indício de um suposto complô para ganhar as eleições pela indignação dos eleitores. No segundo exemplo (imagem 6), as pistas são as mesmas, mas para sugerir um possível estratagema de a esquerda vencer as eleições com o assassinato de Bolsonaro. A autora da postagem se pergunta igualmente quem estaria a pagar os advogados "caríssimos" de Adélio, e questiona por que teria conseguido entrar em um clube de tiros, se não tinha sanidade mental para isso. Esse discurso demarca seu campo cultural ao buscar estabelecer a ligação entre Adélio e a esquerda, argumentando este ter sido filiado ao PSOL, bem como desqualificando o delegado de investigação, pois este teria sido "homem de confiança" da ex-presidente da República Dilma Rousseff, do PT. Os mesmos fatos, portanto, podem ser alegados tanto de um lado, quanto de outro, para se defenderem teses contrárias.

Desse conspiracionismo próprio da RGC, decorre um discurso fortemente marcado pelo pathos $^{23}$ do ressentimento, que, por sua vez, traz em seu bojo outros

${ }^{23}$ Esse elemento passional dos estudos retóricos, talvez muito em função da tradição platônica, foi deixado em segundo plano, com a primazia da dialética socrática em detrimento da sofística. Aristóteles, contudo, reabilita a dignidade da Retórica em sua faceta emotiva. Em sua Retórica, o filósofo dedica um livro inteiro ao tratamento das paixões que, para ele, ao invés de se oporem à verdade, são meios de se sensibilizar alguém para o justo saber (LIMA, 2006). Ressalta Lima (2006), durante a Idade Média, a Retórica, tendo em vista a influência do platonismo na patrística e na escolástica, restringiu-se mais a seus aspectos lógicos, mesmo diante do fato de que o discurso religioso, sobretudo católico, com sua iconografia barroca ostentatória, buscasse atrair os fiéis também pelo encantamento. Depois de Descartes (1996a), a valorização do logos nos estudos retóricos atinge o seu paroxismo, já que o filósofo francês procede a uma separação radical entre uma res extensa e outra res cogitans, entre a "coisa corpórea" e a "coisa pensante", esta a essência do ser, manifestada no "penso, logo existo". Após a Segunda Guerra Mundial, mesmo que os elementos passionais tivessem sido constantemente explorados pelas propagandas dos regimes totalitários, a Retórica ainda guardava um ranço platônico e cartesiano, extirpando as emoções de seu centro de interesse (LIMA, 2006). Só atualmente alguns estudos vêm considerando a importância das emoções da tradição aristotélica, como os de Amossy (2006), Charaudeau (2008), Lima (2006) e Plantin (1996). Amossy se justifica dizendo que: [...] se o 
tipos de emoções, como o ódio, a inveja ou a indignação. Para Angenot (2008), o pensamento conspiratório e a lógica do ressentimento são indissociáveis, uma vez que a conspiração pressupõe a vontade de estabelecer uma relação entre a realidade e um projeto de dominação humilhante e castrador que não se pode provar (ANGENOT, 2008). O conspirador entra em uma estratégia de tentar subverter um modo de produção de sentidos, de imagens identitárias, de valores, de ideias políticas e cívicas dominantes em benefício da absolutização de outros que supostamente encontram-se sob grilhões, pertencentes a um grupo despossuído e reinvidicador (ANGENOT, 2008). Todo insucesso de um grupo ou indivíduo é atribuído ao sucesso alheio:

A lógica do ressentimento postula que a superioridade adquirida no mundo como está é um indício de baixeza moral; que os valores que os dominantes ou os privilegiados possuem devem ser rejeitados e desvalorizados em bloco; que eles são desprezíveis em si mesmos [...] e que toda subordinação, todo fracasso, toda memória do contencioso dão direito ao nobre status de vítima [...]. O ideólogo do ressentimento se coloca em face de um mundo julgado impostor e opressor cultivando queixas [...] que se tornam seu modo exclusivo de contato com o mundo [...], sua grelha hermenêutica. Ele dá uma razão de ser e um mandato social que lhe permitem jamais sair de si mesmo. A queixa determina uma espécie de privatização dos universais éticos e cívicos e formula um programa para o futuro na liquidação de um contencioso acumulado no passado (ANGENOT, 2008, p. 344, tradução nossa $\left.{ }^{24}\right)$.

conhecimento das paixões humanas é apresentado na Retórica [de Aristóteles] como indispensável, é porque ela permite agir pela palavra: ela contribui fortemente para a convicção (AMOSSY, 2006, p. 179, tradução nossa de: "si la connaissance des passions humaines est présentée dans la 'Rhétorique' [d'Aristote] comme indispensable, c'est qu'elle permet d'agir par la parole : elle contribue puissamment à emporter la conviction".

${ }^{24}$ La logique ressentimentiste pose que la supériorité acquise dans le monde tel qu'il va, est un indice de bassesse " morale », que les valeurs que les dominants ou les privilégiés prônent doivent être rejetées et dévaluées en bloc, qu'elles sont méprisables en elles-mêmes [...], et que toute situation subordonnée, tout échec, toute mémoire de contentieux donnent droit au noble statut de victime [...]. L'idéologue du ressentiment se place face à un monde jugé imposteur et oppresseur en cultivant des griefs [qui] devient son mode exclusif de contact avec le monde [...], sa grille herméneutique. Il donne une raison d'être et un mandat social qui permettent cependant de ne jamais sortir de soi-même. Le grief détermine une sorte de privatisation des universaux éthiques et civiques et formule un programme pour l'avenir comme liquidation d'un contentieux accumulé dans le passé. 
Essa axiologia do ressentimento alimenta rancores que se pretendem legítimos e reais, radicalizando e moralizando o ódio, a indignação ou a inveja em relação ao dominante (ANGENOT, 2008). Em uma inversão de valores, o sucesso é o mal em si e a derrota, virtude, já que nada pode reinar inocentemente. $\mathrm{O}$ dominante beneficiário do Sistema será sempre o vilão, o culpado de todo mal pelo simples fato de ocupar sua posição de destaque.

Do discurso do ressentimento, decorre um ethos $^{25}$ de expert (DANBLON, 2010), e um ethos de credibilidade (CHARAUDEAU, 2005), as imagens que o orador confere ao discurso como o de ter sempre razão e de ser credível. Observa Danblon (2010) que, paradoxalmente, apesar de o conspirador se mostrar sapiente, conhecedor das causas primeiras das estruturas de dominação, revelador das relações de poder mais encobertas, ele frequentemente se proclama como um outsider da expertise mainstream:

Ele se apresenta como hipercrítico, rigoroso e preciso, mas, ao mesmo tempo, algo parece lhe dar um acesso direto às causas escondidas [...]. O ethos conspiracionista se dá ao mesmo tempo como aquele do livre pensante da modernidade e como o profeta arcaico capaz de identificar as razões fugidias (DANBLON, 2010, p. 70, tradução nossa ${ }^{26}$ ).

Quanto ao aspecto crível de quem profere um discurso conspiratório, Charaudeau (2005) ressalta que uma das maneiras para conferir credibilidade ao discurso é mostrar que o que se anuncia é seguido de algum efeito na realidade.

\footnotetext{
${ }^{25}$ As análises do ethos são aquelas que "residem no caráter moral do orador, dando a impressão de que ele merece credibilidade" (AMOSSY, 2006, p. 82). De acordo com Maingueneau, "a prova pelo ethos consiste em causar boa impressão pela forma como se constrói o discurso, em dar uma imagem de si capaz de convencer o auditório ganhando sua confiança" (MAINGUENEAU, 2006, p. 53). Para Donot e Emediato (2015), a noção de ethos transcende a noção de prova capaz de suscitar a confiança do auditório, uma vez que mostra igualmente um conjunto de valores mobilizados na sociedade.

${ }^{26}$ Il se présente comme hypercritique, rigoureux et précis, mais, en même temps, quelque chose semble lui donner un accès direct aux causes cachées [...]. L'ethos conspirationniste se donne à la fois comme celui du libre penseur de la modernité et comme celui du prophète archaïque capable de déceler les raisons enfouies.
} 
Acontecido tal efeito, como não há hipótese de refutação, por não haver provas a ser objetadas, mas ilações dogmáticas e precipitadas, a imagem que fica é de que o discurso dispõe de credibilidade (CHARAUDEAU, 2005). É o caso da postagem abaixo:

Imagem 7 - Ethos de expert e de credibilidade.

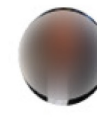

$\theta 0$

(a)-

Suivre

Tenho dito: uma maneira de se analisar o trabalho de um ministro é vendo o quanto a grande imprensa bate nele. Quanto mais bate melhor é o seu trabalho. @SF_Moro @ernestofaraujo @AbrahamWeint

6 Traduire le Tweet
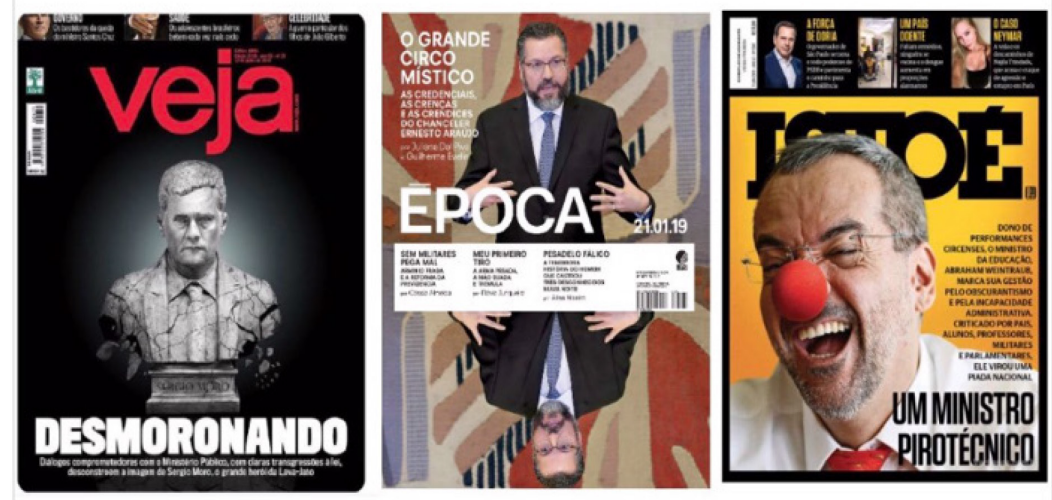

09:18 - 14 juin 2019

1986 Retweets 11170 J'aime

\& Abraham Weintraub et Ernesto Araújo

Q 902 个2 $2,0 \mathrm{k} \quad \mathrm{O}_{11 \mathrm{k}} \quad \square$

Fonte: Twitter 27 .

27 Acesso em: 15 jun. 2019. 
Aqui, um deputado do Partido Social Liberal (PSL), então partido do presidente Bolsonaro, cria uma imagem de sapiente, nesse discurso conspiratório contra a imprensa, na medida em que enuncia uma lei causal generalizante, segundo a qual quanto mais a imprensa submete um ministro a uma apreciação crítica desfavorável, melhor seria o trabalho deste. Para conferir credibilidade ao seu discurso, mostra capas de algumas das principais revistas semanais do Brasil. É como se a imprensa tivesse como ofício trabalhar para o mal do país e, assim, todo político visado por ela, por tabela, possa ser considerado como crível. O ethos de expert fica reforçado com a expressão "tenho dito", o que mostra se tratar de uma afirmação bem pensada há algum tempo e recorrentemente confirmada pelo enunciador.

É nesse sentido que a RGC, com sua orientação frequentemente conspiracionista e rancorosa, encontra terreno fértil no discurso populista, que, para Charaudeau, consiste na radicalização das matrizes ideológicas de esquerda e progressistas, de um lado, e de direita e conservadora, de outro. Para o autor, a cenografia do discurso populista se caracteriza essencialmente por apontar inimigos da nação causadores de todo mal que possam afligir os cidadãos, criando-se a imagem de um líder ou de um governo que seria o único capaz de pacificar o país:

Esse contrato [do discurso populista] faz com que a instância política desenvolva um discurso de acordo com uma cenografia que consiste em denunciar a desordem social da qual os cidadãos são vítimas, pois, se tudo estivesse bem, não haveria razão para se propor um projeto político alternativo; determinar a raiz dessa desordem denunciando os responsáveis; anunciar a solução para colocar fim a essa desordem e promover um estado de ordem social em benefício de todos; concomitantemente, criar uma imagem de líder que se apresente como o único capaz de conduzir um tal projeto (CHARAUDEAU, 2016, p. 34, tradução nossa ${ }^{28}$ ).

\footnotetext{
${ }^{28}$ Ce contrat fait que l'instance politique développe un discours selon une scénographie qui consiste à dénoncer le désordre social dont les citoyens sont victimes, car si tout allait bien, il n'y aurait pas de raison de proposer un projet politique alternatif ; déterminer la source de ce désordre en en dénonçant
} 
Do ponto de vista da RGC, o estado caótico do país é dado como consequência da dominação ideológico/discursiva do grupo cultural oposto. É o caso, por exemplo, do conservador de direita que atribui o analfabetismo funcional que grassa no país, ou as colocações derradeiras em rankings internacionais sobre Educação a uma suposta "doutrinação ideológica" nas escolas, a um "marxismo cultural" ou "ideologia de gênero", termos frequentemente usados nos debates políticos do Brasil. Do outro lado, o campo cultural progressista e de esquerda tende, por exemplo, a culpabilizar pelos altos índices de feminicídio e de mortes de homossexuais e transexuais os partidários dos valores de uma sociedade patriarcal e obscurantista.

De fato, uma estratégia de um grupo para conquistar seu eleitorado em processo de desencantamento com o mundo, diante de uma crise econômica, de desemprego, de falta de perspectiva é encontrar um inimigo sobre o qual possa projetar suas frustrações. Um inimigo que apresente valores, modos de vida, pressupostos, regimes de crenças, cultura, história diferentes daqueles dos que se sentem inferiorizados, espoliados, por exemplo, pela ascensão de uma classe social que antes era subalterna e agora compartilha dos mesmos serviços e empregos oferecidos pela sociedade; ou então se sentem ameaçados pela conquista de direitos por uma minoria antes destituída de dignidade e que, alcançada a igualdade jurídica, coloca em xeque valores tradicionais. Do outro lado, essa mesma minoria pode nutrir uma memória de ressentimento de quando era alijada de condições mínimas de expressão livre de sua identidade e modo de ser.

O discurso populista, no interior da RGC seria, assim, a exacerbação das matrizes ideológicas mencionadas, a progressista de esquerda e a conservadora de direita. Trata-se, portanto, de uma questão de grau. A interação entre essas matrizes

les responsables; annoncer ce qu'est la solution pour mettre fin à ce désordre et promouvoir un état d'ordre social au bénéfice de tous ; concomitamment, créer une image de leader qui se présente comme seul capable de porter un tel projet. 
ideológicas não se dá necessariamente em contexto de guerra cultural, mas esta pressupõe a radicalização daquelas.

Poder-se-ia, com efeito, dizer que o discurso populista seria um traço da RGC, quando enunciado por um representante político, como o deputado do PSL do exemplo acima (imagem 7), quando reproduzido por militantes, ou pela instância midiática que se identifica com eles.

Outra regra que decorre dos pressupostos do debate, para Angenot (2008), é a disposição a argumentar, da qual decorre uma outra, que é a disposição a mudar de ideia. Efetivamente, ao se aceitar entrar em uma discussão, aceita-se, necessariamente, que há um ponto de vista contrário, e que a certeza de um ou de outro não é universalmente aceita. Empreender uma argumentação implica envidar esforços para persuadir alguém que, em princípio, dispõe de visões contrárias em relação ao tópico a ser debatido. Nas palavras de Angenot,

Quem está disposto a debater deve colocar as cartas na mesa, deve fornecer seus argumentos quando se pede e os submeter à apreciação. Discutir, comunicar-se com os outros, não significa afirmar algo unanimemente, confessar publicamente suas convicções, suas certezas e se desresponsabilizar do resto. É preciso também "dar as razões", ao menos é o que se espera [...]. Não expressar suas razões, recusar-se a isso é a forma de violência comunicacional por excelência (ANGENOT, 2008, p. 139, tradução nossa ${ }^{29}$ ).

Corolário da disposição a argumentar é a disposição a mudar de ideia. É que, se a comunicação é pautada pela persuasão, e não pela imposição, é natural que, diante

\footnotetext{
${ }^{29}$ Qui est disposé à débattre doit mettre «carte sur table », il doit donner ses arguments quand on les lui demande et les soumettre à appréciation. Discuter, communiquer avec les autres, ce ne saurait être affirmer tout uniment, confesser publiquement ses convictions, ses certitudes et s'en tenir là. Il faut justement « donner ses raisons », du moins, on s'y attend [...]. Ne pas donner de raisons, refuser d'en donner est la forme par excellence de la violence communicationnelle.
} 
de uma argumentação mais forte que a sua, um interlocutor esteja disposto a abdicar de suas convicções e a aceitar mudar de ideia. Continua Angenot,

Uma regra correlata [...] é aquela segundo a qual todo debatedor deve, antes de entrar em uma discussão e para que esta tenha chance de ser "útil", estar disposto a admitir que é o seu interlocutor que tem razão; é preciso correr o risco de ser conduzido a mudar radicalmente de ideia e de o fazer com boa vontade (ANGENOT, 2008, p. 141, tradução nossa $\left.{ }^{30}\right)$.

No exemplo da imagem 4, quando a autora do tweet diz bloquear o que ela chama de "abutres" de esquerda, ela manifesta, ao mesmo tempo, uma intencionalidade de se furtar ao debate com o campo oposto da regra cultural, bem como de não mudar de ideia no que diz respeito às suas pré-compreensões políticas. De fato, se a autora quer "bloquear" tudo que venha da esquerda, não há trabalho crítico que a faça dissuadir de suas crenças.

Consequentemente, a mesma autora do referido tweet, ao procurar obstaculizar toda fonte de informação que não seja da direita, substitui a crítica responsável no espaço público que se espera de sociedades abertas (DANBLON, 2004) por uma fala coletiva, no caso, de seu campo cultural.

Para Danblon (2004), essa atitude de abolir a posição individual, substituindoa por uma fala coletiva e acreditando estar do bom lado da história de uma vez por todas é ingênua, típica das sociedades mágicas ou fechadas pautadas pelo dogmatismo de concepções:

Ao invés de se considerarem os princípios em sua legitimidade ou em sua pertinência em relação ao debate, ao invés de os examinar com

\footnotetext{
${ }^{30}$ Une règle corrélative [...] est que tout débatteur doit, avant de s'engager dans une discussion et pour que celle-ci ait une chance d'être " utile », être prêt à admettre que c'est son interlocuteur qui a raison ; il faut prendre le risque d'être amené à changer radicalement d'avis et de le faire de bonne grâce.
} 
vistas a criticá-los, reivindicam-se os mesmos na forma de slogans, amalgamando suas vozes a de uma coletividade que confere sua autoridade anonimamente [...]. Ao contrário, em uma sociedade aberta, os valores possuem racionalidade porque são criticáveis. E a crítica é forçosamente individual [...]. Um tal exercício tem o mérito de enfatizar que nenhuma afirmação é em si evidente, que toda posição, mesmo a mais aceita, deve ser argumentada. O hábito do banimento conduz muitos de nós a crer que estão do bom lado da história de uma vez por todas. Em uma sociedade aberta, trata-se de uma ilusão perigosa, cuja inocência conduz diretamente ao dogmatismo (DANBLON, 2004, p. 39-41, tradução nossa ${ }^{31}$ ).

Esse aspecto de tomar uma fala coletiva para, julgando-se do bom lado da história de uma vez por todas, justificar determinada tomada de posição, prescindindo da argumentação crítica própria das sociedades abertas, parece ser um outro traço da RGC.

\section{Considerações Finais}

Através do corpus de apoio representado por postagens e comentários em redes sociais (Twitter e Facebook) nos contextos do vazamento de conversas de autoridades da Lava-Jato e do atentado contra o então candidato a presidente da República do Brasil, Jair Bolsonaro, esperou-se contribuir para pensar o que se denominou aqui de

\section{Retórica da Guerra Cultural (RGC).}

Analisando postagens em que se empreenderam discursos típicos de matrizes ideológicas próprias dos embates culturais, observou-se, em primeiro lugar, a

\footnotetext{
${ }^{31} \mathrm{Au}$ lieu de considérer les principes dans leur légitimité ou dans leur pertinence par rapport au débat, au lieu de les examiner en vue de les critiquer, on les clame comme des slogans, on joint sa voix à la voix d'une collectivité qui puise son autorité de son caractère anonyme [...]. À l'inverse, dans une société ouverte, les valeurs tirent leur rationalité du fait même qu'elles sont critiquables. Or la critique est forcément individuelle [...]. Un tel exercice aurait le mérite de souligner qu'aucune affirmation n'est en soi évidente, que toute position, même parmi les plus partagées, doit s'argumenter. L'habitude de bannissement conduit bon nombre d'entre nous à croire qu'ils sont du bon côté une fois pour toutes. Dans une société ouverte, il s'agit d'une illusion dangereuse dont la naïveté conduit directement au dogmatisme.
} 
“interincompreensão constitutiva" (MAINGUENEAU, 2008) ou o "diálogo de surdos" (ANGENOT, 2008), tendo em vista que os autores das publicações, em diferentes graus, apresentaram dificuldades em escutar as razões do polo oposto e, assim, obstaculizaram o fluxo comunicacional.

Decorrente desse primeiro aspecto, uma outra característica da RGC seria a de ser pautada pela dicotomização, tal como esse conceito é pensado por Amossy (2014). Não se trata da mera polarização inerente a toda argumentação crítica, mas de uma diferenciação entre duas polêmicas públicas, que transcendem um assunto específico ao representarem visões diferentes de mundo que precedem a enunciação.

Em contexto de dicotomização, parece ser frequente, na RGC, a lógica maniqueísta (ANGENOT, 2008), que tende a representar o campo amigo como pertencente a uma verdade absoluta, ao bem supremo, em contraposição ao adversário, o vilão por excelência, responsável por toda a decadência moral do mundo.

Corolário de todos esses fatores, a linguagem da RGC apresenta-se como unifocal (MAINGUENEAU, 2008), no sentido de que existe uma visada de aniquilação da voz do adversário. Não que um discurso próprio dos embates culturais não seja dialógico, pensando naquela categoria do dialogismo constitutivo proposta por Bakhtin (1992). É que, em função da radicalidade dos propósitos da guerra cultural, o número de marcas textuais que remetem às razões do discurso adversário, como elementos que exprimem concessão e transigência, tende a diminuir.

Caracterizar-se-ia, ainda, a RGC, pela recorrente infração às regras do estilo (ANGENOT, 2008), com o uso de termos que denotam violência verbal por parte do enunciador que, incapaz de escutar as razões alheias e de, por meio delas, conduzir uma argumentação crítica, parte para o insulto, ferindo as faces positiva e negativa (BROWN; LEVINSON, 1997) do adversário.

Um outro traço da RGC seria o desprezo pelas regras do suporte ou do contrato de comunicação estabelecido entre os parceiros, normalmente ferindo a regra da 
pertinência (ANGENOT, 2008; GRICE, 1979), ao se desviar do assunto para a imposição da pauta cultural do locutor.

A RGC também se apresenta como aquela em que se percebe a infração àquilo que Angenot (2008) denomina de "regras do debate", com a inversão do ônus da prova, por meio da retórica conspiratória e da denunciação (DANBLON, 2004). Nesse caso, o falante se desresponsabiliza por suas acusações, deixando de fundamentá-las e obstaculizando, assim, a argumentação crítica do espaço público das sociedades abertas. Essa ausência de fundamentação faz com que a RGC se apresente sob as vestes de um discurso dogmático infantilizado, e, às vezes, populista, já que a ênfase está na proteção de quem acusa, e não em sua responsabilidade de fornecer provas (DANBLON, 2004).

No caso da retórica da conspiração, esta pressupõe um pathos de ressentimento (acompanhado do ódio, da inveja e/ou da indignação) de se estar no polo passivo de uma suposta relação de dominância proporcionada por um complô de forças secretas, das quais o falante se regozija de pretender descobrir os mecanismos, sem oferecer provas para tal (ANGENOT, 2008).

É por isso que se pode dizer, também, que, na RGC, prevalece um ethos de expert (DANBLON, 2004), porque, apesar de se declarar um outsider do sistema e, portanto, distante do meio acadêmico mainstream, o orador deixa transparecer sua capacidade de desvelar pretensas relações espúrias de dominação que estão a deixá-lo em sua posição atual de inferioridade (ANGENOT, 2008).

A esse ethos de expert, junta-se um ethos de credibilidade (CHARAUDEAU, 2005), exatamente pelo fato de o conspirador se mostrar distante das forças que ele condena ("capital", "grande mídia", "professores doutrinadores" etc.), revelando-se, assim, "purificado" e livre de suspeitas.

Pode-se mencionar, finalmente, que a RGC se apresenta como aquela em que os sujeitos se mostram como indispostos a argumentar e a mudar de ideia, o que, para 
Angenot (2008), seria mais um caso de infração das regras do debate, podendo-se acrescentar, com Danblon (2004), infração sobretudo às regras do debate democrático das sociedades abertas. É que não faz sentido entrar em um debate crítico, buscar fundamentos, se tudo será em vão, se os interlocutores já se indispõem, a priori, a saírem de si, a se descentrarem e a entenderem as razões do outro, permanecendo em seu campo cultural.

Em resumo, a RGC poderia ser caracterizada como no seguinte quadro, o que pode ser testado futuramente por outros pesquisadores por meio de outros corpora e contextos de análise. Trata-se de uma tendência de características que podem aparecer em menor ou maior grau, a depender do caso específico:

Quadro 1 - Retórica da Guerra Cultural.

\section{Retórica da Guerra Cultural}

- Interincompreensão

- Dicotomização

- Unifocalidade

- Desproteção das faces

- Maniqueísmo

- Desvio do assunto

- Crítica substituída por uma fala coletiva

- Inversão do ônus da prova

- Dogmatismo

- Infantilização

- Populismo

- Denuncismo

- Conspiracionismo

- Pathos de ressentimento, ódio, inveja e/ou indignação

- Ethos de expert e de credibilidade

- Indisposição a argumentar e a mudar de ideia

Fonte: elaboração do autor. 
Seria ingênuo defender a inexistência de fraturas ideológicas sociais, de divergências de visões de mundo, de valores e de regimes de verdades. Em um Estado Democrático de Direito, é desejável que essas diferenças coexistam. O problema talvez esteja na forma de gerir o conflito, sem uma estruturação de base do espaço público que permita que os mais diversos atores sociais compreendam a palavra alheia e possam, assim, proceder à argumentação crítica (inclusive dos valores os mais sacralizados) afeita a uma sociedade aberta.

Assim, espera-se que esta pesquisa, além de contribuir para a compreensão dos mecanismos próprios da RGC, também que possa inspirar, indiretamente, educadores a pensar em modelos educativos que priorizem a gestão do debate público por meio da argumentação crítica, que pressupõe o respeito, a tolerância, a escuta e o pluralismo de ideias, tendo em vista a preservação das instituições democráticas. Temas para outros trabalhos.

\section{Referências}

ALTHUSSER, L. Aparelhos ideológicos do Estado. Rio de Janeiro: Graal, 1998.

AMOSSY, R. Apologie de la polémique. Paris: Presses Universitaires de France, 2014.

AMOSSY, R. L'argumentation dans le discours. Armand Colin: Paris, 2006. DOI https://doi.org/10.3917/puf.amos.2014.01

ANDRADE, M. L. C. V. O; FÁVERO, L. L. Cortesia verbal e ensino de língua: reflexões sobre competência comunicativa, jogo interpessoal e normatividade. Filologia e Linguística portuguesa, São Paulo, v. 17, n. 1, p. 101-129. jan./jun. 2015. Disponível em: http://www.revistas.usp.br/flp/article/view/109108. Acesso em: 18 nov. 2019. DOI https://doi.org/10.11606/issn.2176-9419.v17i1p101-129

ANGENOT, M. Dialogues de sourds: traité de rhétorique antilogique. Paris: Mille et une nuits, 2008.

BAKHTIN, M. Marxismo e filosofia da linguagem. São Paulo: Hucitec, 1992. 
BAYLEY, S. Robert Mapplethorpe: bad boy with a camera. The Spectator. 02 de abr. 2016. Disponível em: https://www.spectator.co.uk/2016/04/robert-mapplethorpe-badboy-with-a-camera/. Acesso em: 06 nov. 2019.

BOLSONARO DIZ que oposição terá culpa e benefícios de mais pobres forem cortados. Folha de S. Paulo. 09 de jun. 2019. Disponível em: https://www1.folha.uol.com.br/mercado/2019/06/bolsonaro-diz-que-oposicao-teraculpa-se-beneficios-de-mais-pobres-forem-cortados.shtml. Acesso em: 06 nov. 2010.

BROWN, P.; LEVINSON, S. Politeness. Cambridge: Cambridge University Press, 1987. DOI https://doi.org/10.1017/CBO9780511813085

BUCHANAN, P. J. A contract with the unborn. Reading List. 21 jan. 1995b. Disponível em: http://www.theamericancause.org/contract.htm. Acesso em: 15 nov. 2019.

BUCHANAN, P. J. 1996 Announcement Speech. Articles, Letters, and Speeches. 20 de mar. $1995 . \quad$ Disponível em: https://web.archive.org/web/20061211120515/http:/www.buchanan.org/pa-95-0320announce.html. Acesso em: 15 nov. 2019.

BUCHANAN, P. J. Can America Transcend Race? The American Cause. 24 de set. 2003. Disponível em: http://www.theamericancause.org/patcanamericatranscendrace.htm. Acesso em: 06 nov. 2019.

BUCHANAN, P. J. Is Catholicism now 'unacceptable'? The American Cause. 20 de jun. 2006. Disponível em: http://www.theamericancause.org/print/062006 print.htm. Acesso em: 15 nov. 2019.

BUCHANAN, P. J. The aggressors in the culture wars. The American Cause. 8 de mar. 2004. Disponível em: http://www.theamericancause.org/patculturewars.htm. Acesso em: 15 nov. 2019.

BUCHANAN, P. J. The death of the West. 14 de jan. 2002. Common Wealth Club. Disponível em: https://web.archive.org/web/20090116001625/http:/www.commonwealthclub.org/arc hive/02/02-01buchanan-speech.html. Acesso em: 15 nov. 2019.

CHARAUDEAU, P. Du discours politique au discours populiste. Le populisme est-il de droite ou de gauche? In: CORCUERA, F. et alii (org.). Les discours politiques. Regards croisés. Paris: L'Harmattan, 2016. p. 32-43. 
CHARAUDEAU, P. Le discours politique: les masques du pouvoir. Paris: Librairie Vuibert, 2005.

DANBLON, E. Argumenter en démocratie. Bruxelles: Éditions Labor, 2004.

DANBLON, E. Les 'théories du complot' ou la mauvaise conscience de la pensée moderne. In: DANBLON, E.; NICOLAS, L. Les rhétoriques de la conspiration. Paris: CNRS Éditions, 2010. DOI https://doi.org/10.4000/books.editionscnrs.16202

DEJEAN, J. Ancient against moderns. Culture Wars and the Making of a Fin de Siècle. Chicago: University of Chicago Press, 1989.

DESCARTES, R. Discurso do Método. São Paulo: Nova Cultural, 1996.

DONOT, M.; EMEDIATO, W. La construction de la figure des leaders: ethos, identité et charisme en perspective compare. Revue française des sciences de l'information et de la communication, n. 7, 2015. Disponível em: https://journals.openedition.org/rfsic/1588?lang=en. Acesso em: 18 nov. 2019. DOI https://doi.org/10.4000/rfsic.1588

ENVIRONMENTALISM is yet another new religion. On the Issues. 18 de out. 2011. Disponível em: https://www.ontheissues.org/Celeb/Pat Buchanan Environment.htm. Acesso em: 16 nov. 2019.

EMÍLIO SURITA é criticado por frase machista contra jornalista. R7 Planalto. 13 de jun. 2016. Disponível em: https://noticias.r7.com/prisma/r7-planalto/emilio-surita-ecriticado-por-frase-machista-contra-jornalista-13062019. Acesso em: 16 nov. 2019.

FOUCAULT, M. Arqueologia do saber. Rio de Janeiro: Forense Universitária, 2012.

FRIZELL, S. GOP shows white supremacist's tweet during Trump's speech. Time. 22 de jul. 2016. Disponível em: https://time.com/4418591/republican-convention-whitesupremacist-tweet/. Acesso em: 16 nov. 2019.

GALHARDO, R.; TRUFFI, R. Secretário de cultura defende mudanças nos mecanismos de controle da Lei Rouanet. Terra. 02 de jan. 2019. Disponível em: https://www.terra.com.br/noticias/brasil/politica/secretario-de-cultura-defendemudancas-nos-mecanismos-de-controle-da-leirouanet,07173c44872fd97c6a03a8737f3d3d8dx5j521ba.html. Acesso em: 16 nov. 2019. 
GLOBALISM, a far-right conspirancy buoyed by Trump. The New York Times. 03 de mar. 2016.2 Disponível em: https://www.nytimes.com/2016/11/15/us/politics/globalism-right-trump.html. Acesso em: 17 nov. 2019.

GOFFMAN, E. Les rites d'interaction. Paris: Éditions de Minuit, 1974.

GREENWALD, G.; MARTINS, R. M.; SANTI, A. de. Não é muito tempo sem operação?. The Intercept Brasil. 09 de jun. 2019. Disponível em: https://heintercept.com/2019/06/09/chat-moro-deltan-telegram-lava-jato/. Acesso em: 17 nov. 2019.

GRICE, P. Logique et conversation. Comunications, n. 30, 1979. DOI https://doi.org/10.3406/comm.1979.1446

GROSS, M. Kulturkampf and Unification: German Liberalism and the War Against the Jesuits. Cambridge, Central European History, v. 30, n. 4, 1997, p. 545-566. DOI https://doi.org/10.1017/S000893890001565X

HUNTER, J. D. Culture Wars: the struggle to define America. New York: Basic Books, 1991.

KERBRAT-ORECCHIONI, C. Les Interactions verbales. Paris: Armand Colin, 1990.

LIMA, H. M. R. de. Na tessitura do Processo Penal: a argumentação no Tribunal do Júri. 2006. 260f. Tese (Doutorado) - Universidade Federal de Minas Gerais, Programa de Pós-Graduação em Linguística. Belo Horizonte, 2006.

MAINGUENEAU, D. Cenas de Enunciação. Curitiba: Criar, 2006.

MAINGUENEAU, D. Discurso e Análise do Discurso. Trad. Sírio Possenti. 1 ed. São Paulo: Parábola, 2015.

MAINGUENEAU, D. Gênese dos Discursos. Curitiba: Criar, 2008.

MAINGUENEAU, D. L'Analyse du Discours: introduction aux Lectures de L'archive. Hachette Université Linguistique. Université d'Amiens, Paris, 1991.

MAINGUENEAU, D. Sémantique de la polémique: discours religieux et ruptures idéologiques au XVII siècle. Lausanne: 1'Âge d'Homme, 1983. 
MALDIDIER, D. A inquietação do discurso. Campinas: Pontes, 2003.

OLIVEIRA, E. Araújo promove seminário sobre 'globalismo' em fundação ligada ao Itamaraty. O Globo. 23 de mai. 2019. Disponível em: https://oglobo.globo.com/mundo/araujo-promove-seminario-sobre-globalismo-emfundacao-ligada-ao-itamaraty-23689188. Acesso em: 17 nov. 2019.

PAT BUCHANAN`S response to Norman Podhoretz's OP-ED. Internet Brigade. 5 de nov. $1999 . \quad$ Disponível em: https://web.archive.org/web/20081008152726/http:/www.buchanan.org/pma-99-1105wallstjl.html. Acesso em: 17 nov. 2019.

PÊCHEUX, M. Análise Automática do Discurso (AAD-69). In: GADET, F.; HAK, T. (org.). Por uma análise automática do discurso: uma introdução à obra de Michel Pêcheux. Campinas: Editora da UNICAMP, 1997. p. 61-162.

PÊCHEUX, M. Les vérités de la palice. Paris: F. Maspero, 1975.

PLANTIN, C. L’Argumentation. Paris: Seuil, 1996.

POLIAKOV, L. La causalité diabolique: essai sur l'origine des persécutions. Paris: Calmann-Lévy, 1980.

QUADROS, M. P. dos R. O conservadorismo à brasileira: sociedade e elites políticas na contemporaneidade. 2015. 273f. Tese (Doutorado) - Pontifícia Universidade Católica do Rio Grande do Sul, Programa de Pós-Graduação em Ciências Sociais. Porto Alegre, 2015.

REALE, G.; ANTISERI, D. História da Filosofia: de Freud à atualidade, v. 7. São Paulo: Paulus, 2005.

SAYURI, J. O que é 'guerra cultural'. E por que a expressão está em alta. Nexo. 10 de mar. 2019. Disponível em: https://www.nexojornal.com.br/expresso/2019/03/10/Oque-é-'guerra-cultural' .-E-por-que-a-expressão-está-em-alta. Acesso em: 18 nov. 2019.

VANDERFORD, M. L. Vilification and Social Movements: a case-study of pro-life and pro-choice rhetoric. Quarterly Journal of Speech, 75, p. 166-182, 1989. DOI https://doi.org/10.1080/00335638909383870

WILLIAMS, R. Culture Wars in American Politics. Critical reviews of a popular myth. New York: Walter de Gruyter, 1997. 